\title{
Quand combat et revendication kanak ou politique de l'État français manient indépendance, décolonisation, autodétermination et autochtonie en Nouvelle-Calédonie
}

\section{Stéphanie GRAFF}

\section{OpenEdition}

Journals

Édition électronique

URL : https://journals.openedition.org/jso/6647

DOI : $10.4000 /$ jso.6647

ISSN : $1760-7256$

Éditeur

Société des océanistes

Édition imprimée

Date de publication : 30 juin 2012

Pagination : 61-83

ISBN : 978-2-85430-032-1

ISSN : 0300-953x

Référence électronique

Stéphanie GRAFF, «Quand combat et revendication kanak ou politique de l'État français manient indépendance, décolonisation, autodétermination et autochtonie en Nouvelle-Calédonie », Journal de la Société des Océanistes [En ligne], 134 | 1er semestre 2012, mis en ligne le 12 juillet 2012, consulté le 21 septembre 2021. URL : http://journals.openedition.org/jso/6647 ; DOI : https://doi.org/10.4000/jso. 6647

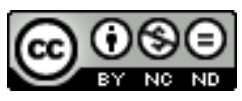

Journal de la société des océanistes est mis à disposition selon les termes de la Licence Creative Commons Attribution - Pas d'Utilisation Commerciale - Pas de Modification 4.0 International. 


\section{Quand combat et revendications kanak ou politique de l'État français manient indépendance, décolonisation, autodétermination et autochtonie en Nouvelle-Calédonie ${ }^{1}$}

par

Stéphanie GRAFF*

\section{RÉSUMÉ}

Cet article est une étude de l'interprétation et de la mise en auvre des concepts d'"indépendance », de "décolonisation », d'« autodétermination », d'" autochtonie » dans les revendications kanak et la politique française en matière de droits des pays et peuples coloniaux et de droits des peuples autochtones. Au regard du droit international, le peuple kanak est autochtone et colonisé. La Nouvelle-Calédonie est inscrite sur la liste des pays à décoloniser des Nations unies depuis 1986. Quelles ont été, à travers l'histoire et jusqu'à aujourd'hui, les stratégies politiques et juridiques choisies par le peuple kanak pour avancer dans ses revendications et quel a été le positionnement de l'État français vis-à-vis de ces revendications pour protéger ses intérêts?

MotS-CLÉS : Indépendance, décolonisation, autodétermination, autochtonie, stratégies politiques, revendications kanak, Nouvelle-Calédonie, Nations unies, France

Depuis 2005, les recherches menées dans le cadre de ma thèse (inscrite officiellement en 2008) concernent l'étude des représentations locales des notions d'« indépendance », de " décolonisation », d'« autodétermination », d'« autoch-

\begin{abstract}
This article is a study of the interpretation and the implementation of the concepts of "independence", "decolonization", "self-determination", “autochthony" in the Kanak claims and the French policy regarding the rights of colonial countries and peoples and indigenous peoples' rights. In international law, Kanak people are indigenous and colonized. Since 1986, New Caledonia is on the UN list of Non-Self-Governing Territories. What have been, throughout history and until today, the political and legal strategies chosen by Kanak people to advance their claims and what was the position of the French state vis-à-vis these claims to protect its interests?
\end{abstract}

KEYWORDS: Independence, decolonization, selfdetermination, autochthony, political strategies, Kanak claims, New Caledonia, United Nations, France

tonie », avec une comparaison de l'interprétation et de la mise en œuvre des droits des peuples autochtones et des droits des pays et peuples coloniaux au regard de la situation en NouvelleCalédonie, à travers plusieurs acteurs (oNU, État

1. Je remercie tous ceux qui me soutiennent dans mes recherches universitaires, mais aussi ceux avec qui j'effectue d'autres travaux, non universitaires, en Nouvelle-Calédonie, en France, à Genève et à New-York. Merci à Isabelle-Schulte-Tenckhoff, Denis Monnerie et Isabelle Leblic, pour leurs commentaires et conseils sur ce texte.

* Doctorante en études du développement à l'IHEID à Genève et membre associée du Laboratoire Culture et Sociétés en Europe, Université de Strasbourg, stephanie_graff@hotmail.com 
français, gouvernement de Nouvelle-Calédonie, FLNKS, ONG kanak), sur plusieurs niveaux (international, national, local), et à partir d'enquêtes multisituées avec une expérience de terrains d'environ trois ans et demi en NouvelleCalédonie et au sein des Nations unies (stage à l'Unité de décolonisation à New York, stage au sein du Bureau du Rapporteur spécial sur les droits des peuples autochtones et participation au Mécanisme d'Experts sur les droits des peuples autochtones à Genève) ${ }^{2}$. Par ailleurs, à la demande de Benoît Tangopi, ancien prisonnier politique d'Ouvéa, je prépare avec lui un recueil de témoignages sur le drame de la grotte d'Ouvéa qui eut lieu en 1988. Ce travail de terrain, en cours depuis 2008, est en voie d'achèvement. À ce jour, 118 témoignages ont été recueillis. Au regard de cette recherche, j'effectue également une analyse du film de Mathieu Kassovitz L'Ordre et la morale, ayant été confrontée sur place, comme en France, à la réalisation de ce projet. À partir de cette longue pratique de terrain, je vais revenir ici sur certaines notions au centre de cette recherche.

« Indépendance », « décolonisation », « autodétermination ${ }^{3} »$, « autochtonie » sont, au cœur des enjeux de l'avenir institutionnel et statutaire de la Nouvelle-Calédonie ${ }^{4}$. Ainsi, lors de meetings politiques, réunions d'associations militantes ou encore, récemment, lors du comité de pilotage «Après 2014 », ces termes sont l'objet d'intérêts et de combats qui suscitent la mise en place de stratégies politiques et juridiques selon des objectifs propres à atteindre. Entre 2014 et 2018, une partie de la population devra s'exprimer par vote pour déterminer l'avenir institutionnel et statutaire du territoire. L'issue de cette consultation électorale ${ }^{5}$ doit permettre de définir quelle forme d'autodétermination pour le territoire de Nouvelle-Calédonie et pour ses habitants. L'avenir semble encore incertain. Dans la France? Avec la France? Sans la France?

En effet, le mécanisme de l'accord de Nouméa et la loi $\mathrm{n}^{\circ}$ 99-209 du 19 mars 1999 organique relative à la Nouvelle-Calédonie prévoient qu'au cours du mandat du Congrès commençant en 2014, une partie de la population, définie par un corps électoral restreint et considérée aujourd'hui comme les " citoyens de Nouvelle-Calédonie », aura à s'exprimer sur l'accession à la pleine souveraineté du territoire lors d'une consultation électorale dont la question sera définie par décret en conseil des ministres après consultation du gouvernement de NouvelleCalédonie. D'autre part, pour que cette consultation électorale ait lieu, il faut que les trois cinquièmes des membres du Congrès le demandent (Wamytan, 2003). Cette consultation électorale sur l'accession à la pleine souveraineté, ou plutôt un référendum sur l'indépendance est en outre demandé par les indépendantistes depuis qu'ils revendiquent l'indépendance (voir « Communiqué à l'issue de la réunion de La Conception », in Leblic, 1993 : 60-61). De même, lors la table ronde de Nainville-les-Roches (voir doc. du secrétariat d'État aux DOM-TOM, 5 jours à Nainville-les-Roches), un référendum sur l'indépendance fut demandé par les indépendantistes. Les accords de Matignon prévoyaient cette consultation pour 1998 (accords de MatignonOudinot, point 6) mais celle-ci n'a pas eu lieu et, à la place, a été signé l'accord de Nouméa qui repoussait ce vote à 2014. Jusqu'à présent, cette consultation n'a pas été faite. Un transfert progressif et irréversible des compétences, inscrit dans l'accord de Nouméa, est prévu avant la consultation électorale sur l'accession à la pleine souveraineté.

L'histoire a montré que la nature de la question (sur la forme d'autodétermination et pour qui) est au cœur des conflits et des négociations que le peuple kanak a eus et a toujours avec l'État qui l'a colonisé et a colonisé les terres sur lesquelles il vivait ou évoluait, et ce depuis les débuts de la colonisation.

\section{La perte et la tentative de regain de souveraineté}

Si la présence européenne et/ou étrangère est, en Nouvelle-Calédonie, antérieure à la prise de possession par la France ${ }^{6}$, la perte de la souveraineté au niveau du droit international se date le 24 septembre 1853, lorsque la France prit

2. Ces recherches sont, depuis 2009, soutenues par l'Agence nationale de la recherche au travers du projet LocNatPol: Logiques locales - logiques nationales : mutations politiques dans trois pays dits mélanésiens (référence ANR-09-BLAN-0320-01).

3. Dans cet article, l'usage des termes et expressions « autodétermination » et/ou « droit à l'autodétermination » renvoie au « droit des peuples à disposer d'eux-mêmes ». C'est en partant de ce point que seront analysées l'interprétation et l'application qui en sont faites par l'État français et dans les revendications kanak.

4. Ce pays fut nommé New Caledonia par James Cook qui débarqua sur ses côtes en 1774 et y trouva une ressemblance avec son Écosse natale (Saussol, $1979: 17$ ).

5. L'expression « consultation électorale » sera utilisée dans cet article car c'est ce qui est prévu dans l'accord de Nouméa, et non pas le concept de « référendum ».

6. Les missionnaires sont arrivés en Nouvelle-Calédonie aux alentours de 1840 et avant eux des baleiniers et des santaliers notamment se rendaient déjà en Nouvelle-Calédonie pour leur commerce (Saussol, 1979: 17). 


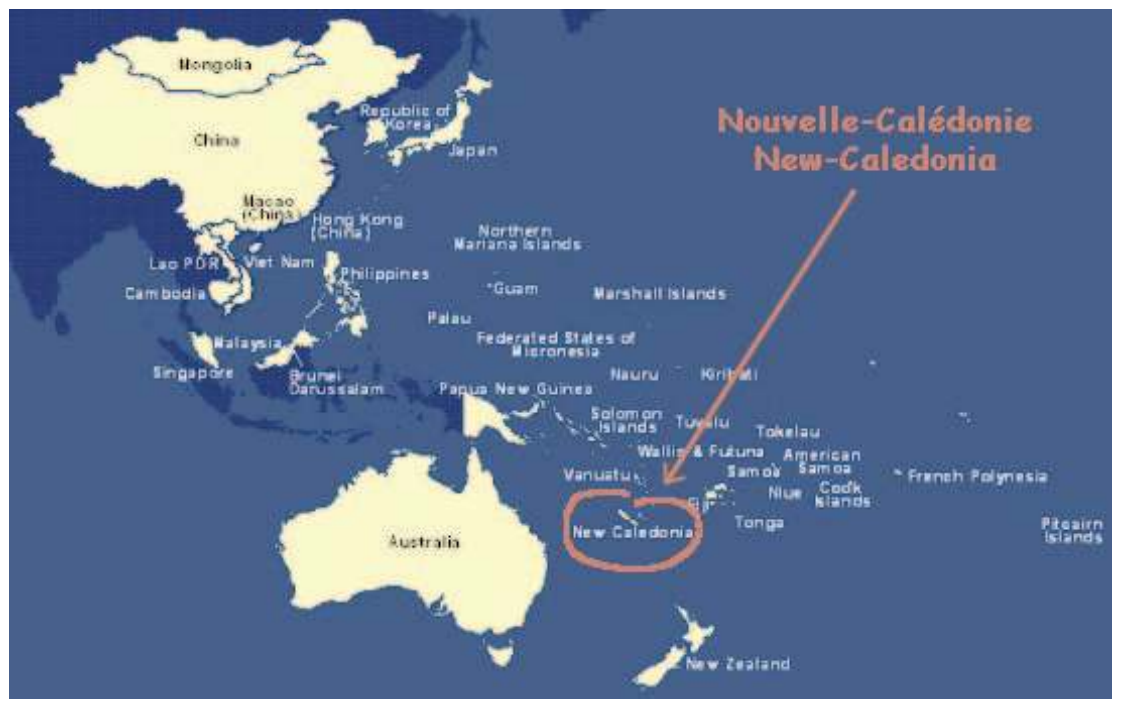

CARTE 1. - : Localisation de la Nouvelle-Calédonie dans le Pacifique Sud (http://www.radioalgerie.dz/fr/index.php?option= com_content\&view=article\&id=10044: nouvelle-caledonie-des-milliers-de-manifestants-contre-la-vie-chere\&catid=26:asie -pacifique\&Itemid=166, consulté le 26/04/2012)

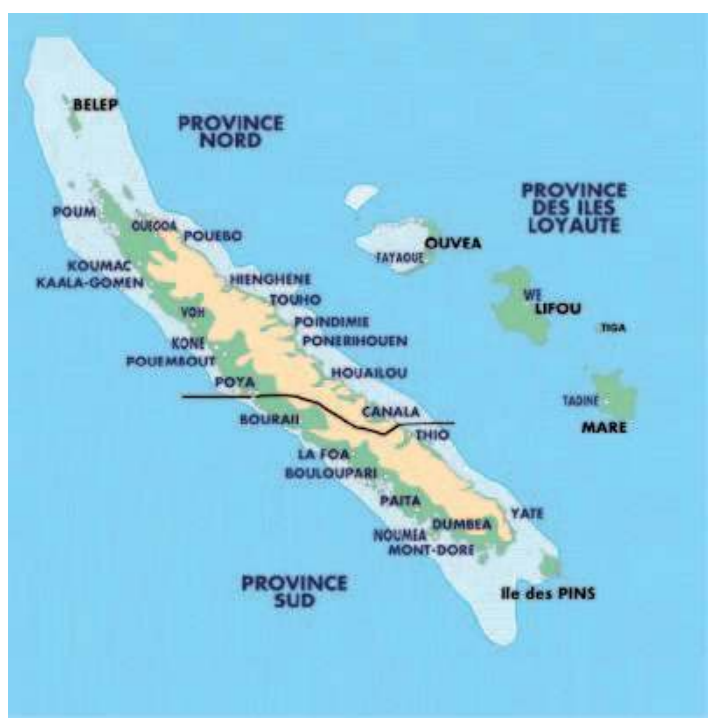

CARTE 2. - La Nouvelle-Calédonie (http://denouvellecale donie.blogspot.com/2010/07/carte-de-la-nouvelle-caledo nie.html, consulté le 26/04/2012)

possession de la Nouvelle-Calédonie ( $c f$. Copie du procès verbal de la prise de possession de la Nouvelle-Calédonie et de ses dépendances par le Contre-amiral Febvrier Despointes).

Les premières revendications kanak contre ce fait colonial ont commencé peu de temps après. Il y eut notamment la célèbre révolte dite d'Ataï, en 1878, durant laquelle le chef Ataï fut tué et décapité. Son crâne est toujours conservé en France, dans des collections anthropologiques physiques au Muséum national d'histoire naturelle, macabre vestige colonial ${ }^{7}$. Puis, de 1887 à 1946, les Kanak furent :

« [...] soumis au régime de l'Indigénat; celui-ci leur interdit de quitter le territoire des réserves, les prive de la citoyenneté française et de tous les droits civiques et les exclut du droit commun. Les Kanak ne peuvent sortir des réserves que pour s'acquitter de l'impôt de capitation et du travail obligatoire au profit des colons et du territoire (arrêté du 6 mai 1871 et du 6 mars 1876). » (Leblic, 1993 : 7)

La Nouvelle-Calédonie fut d'abord colonie pénitentiaire avec la présence de bagnes, puis colonie de peuplement avec l'appropriation des terres par des colons pourl'exploitation des sols et des sous-sols, en particulier les mines de nickel. Le régime de l'Indigénat fut aboli en 1946. Puis, jusqu'en 1988, le territoire fut soumis successivement à sept statuts différents lui consacrant tantôt plus, tantôt moins d'autonomie.

Avec le projet de «Communauté » du Général De Gaulle (qui fait suite à l'Union française) est encouragée et mise en place l'immigration de Métropolitains vers les départements et territoires d'Outre-mer ${ }^{8}$ (Leblic, 1993 ; Baissat, 2006). Les besoins en main-d'œuvre et, notamment, le

7. Des pourparlers sont en cours pour le retour du crâne d'Ataï en Nouvelle-Calédonie (Les Nouvelles calédoniennes, Le retour d'Ataï ?, publié le 07/07/2011, http://www.lnc.nc/article/pays/le-retour-d\%E2\%80\%99atai, consulté le 29/04/2012).

8. À partir de 1956 et suite aux guerres d'Indochine et d'Algérie, des transferts de populations, de la Métropole vers les DOM-TOM, mais aussi des DOM-TOM vers la Métropole, ont été mis en place par le gouvernement français de l'époque (Constant, $1987: 11)$ 


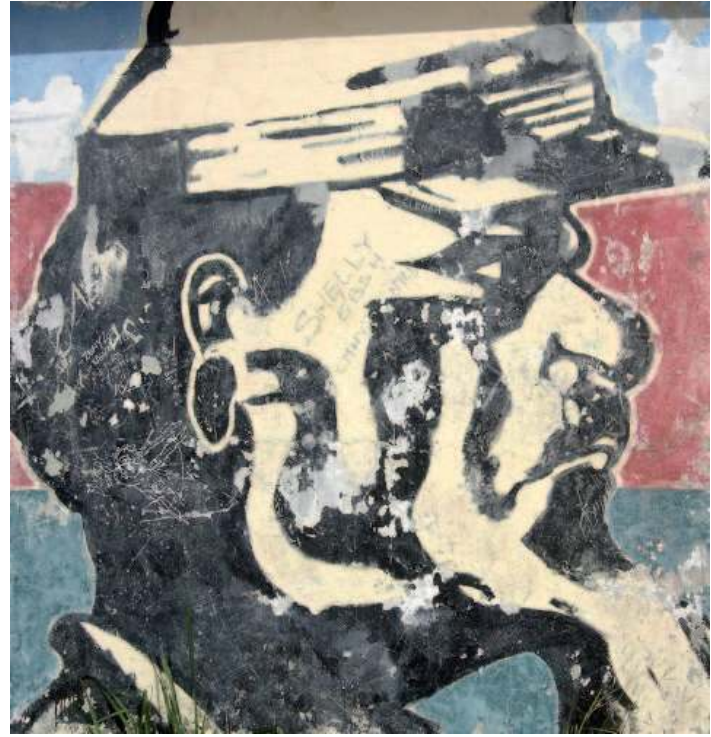

Рното 1. - Graffiti d'Ataï sur un abri de bus à Hienghène. Ataï est devenu pour les jeunes kanak un symbole de la résistance (http://meoukison.free.fr/article.php3?id_article $=146$ )

boom du nickel du début des années 1970 légitimeront ensuite cette politique d'immigration vers le territoire (voir la Lettre de Pierre Messmer, Premier ministre, à Jean-François Deniau, secrétaire d'État aux DOM-TOM, datant du 19 juillet 1972, in Gabriel \& Kermel, 1985 : 51).

Ainsi, de nombreuses communautés arrivèrent pour travailler dans le domaine de l'exploitation du nickel, par ordre alphabétique les Futuniens, Indonésiens, Javanais, Tahitiens, Vietnamiens, Wallisiens, etc. Le peuple kanak devient alors de plus en plus minoritaire en Nouvelle-Calédonie (Leblic, 1993: 31, tableau «Évolution de la population calédonienne (1853-1989) »).
Face à cette situation, les Kanak s'organisent peu à peu politiquement. D'abord les revendications furent autonomistes ${ }^{9}$, puis, peut-être encouragées par les vagues d'indépendance mondiales des années 1960, et des années 1970 pour certains pays de la région du Pacifique ${ }^{10}$, elles devinrent des revendications d'indépendance. En interne, il y eut aussi l'influence de jeunes étudiants kanak partis en France pour leurs études et revenus en Nouvelle-Calédonie ${ }^{11}$. Parmi les mouvements contestataires au sein desquels se regroupèrent ces étudiants, on peut citer les Foulards rouges et le Groupe 1878. Ainsi, la proclamation officielle de l'indépendance kanak est datée du 22 juin 1975 (cf. le programme du Front uni de Libération kanak [FULK] pour les élections à l'Assemblée territoriale le 11 septembre 1977). Suite à cela, en juillet 1975, les Foulards rouges et le Groupe 1878 se regroupèrent pour créer le parti politique PALIKA (Parti de libération kanak) (Leblic, 1993: Annexe II - Généalogie du paysage politique de la Nouvelle-Calédonie). L'Union calédonienne ${ }^{12}$ se prononcera pour l'indépendance en 1977 à Bourail, lors de son congrès (Leblic, $1993: 61)$.

D'après Hnihnö Wea (entretien du jeudi 23 février 2012), à l'époque ministre des Finances du Gouvernement provisoire de Kanaky, Yann Céléné Uregei, leader de l'Union multiraciale (puis du FULK et qui sera ministre des Relations extérieures du Gouvernement provisoire de Kanaky à partir de décembre 1984), est le premier Kanak à se rendre en 1978 aux Nations unies à New York, au Comité de décolonisation, appelé aussi Comité des 24, pour y revendiquer l'indépendance de son peuple et de son pays.

9. Voir notamment le programme de l'Union Multiraciale pour les élections législatives du 4 et 11 mars 1973.

10. Tous les pays du Pacifique Sud qui accédèrent à l'indépendance le firent entre 1970 et 1980. Le premier pays de la région à y accéder fut les Samoa occidentales en 1962. Puis ce furent Fiji et Tonga en 1970, la Papouasie Nouvelle-Guinée en 1975, Tuvalu et les Îles Salomon en 1978, puis le Vanuatu en 1980 (Foster, 1995 : 33). Aujourd'hui, seule la Nouvelle-Calédonie, la Polynésie française, Wallis-et-Futuna, les Samoa américaines, Guam, Tokelau, Pitcairn et la Papouasie occidentale ne sont pas indépendantes. (FosTER, $1995: 26$, note de bas de page 1, complété par nous pour ceux en gras).

11. Parmi d'autres, nous pouvons citer : Nidoish Naisseline, grand chef du district de Guahma à Maré, fondateur des Foulards rouges, puis du LKS (Libération kanak socialiste), actuellement membre du congrès de la Nouvelle-Calédonie et vice-président de la province des Îles Loyauté ; Déwé Görödé, militante du Groupe 1878 et fondatrice du PALIKA, membre du FLNKS, actuellement membre du gouvernement de la Nouvelle-Calédonie en charge de la citoyenneté, de la culture et de la condition féminine ; Élie Poigoune, militant du Groupe 1878 puis fondateur du PALIKA, actuellement président de la Ligue des Droits de l'Homme de Nouvelle-Calédonie; Rock Wamytan, aujourd'hui grand chef de Saint-Louis, membre de l'Union calédonienne, président du FLNKS de 1995 à 2001, président du Groupe mélanésien Fer de Lance de juillet 2001 à juillet 2003, signataire de l'accord de Nouméa, actuellement président du congrès de Nouvelle-Calédonie; Paul Néaoutyine, militant des Foulards rouges puis du Groupe 1878, fondateur du PALIKA, président du FLNKS de 1990 à 1995, actuellement président de la province Nord.

12. Fondé en 1953 de la fusion de l'uicalo (Union des Indigènes calédoniens amis de la liberté dans l'ordre) et de l'AiCLF (Association des Indigènes calédoniens et loyaltiens français), l'Union calédonienne est au départ un parti politique autonomiste dont le slogan était « Deux couleurs, un seul peuple ». La division entre les autonomistes et les indépendantistes au sein du parti se fait en 1977 lorsque les jeunes générations (Jean-Marie Tjibaou, Éloi Machoro) sont soutenues par leurs aînés (Roch Pidjot, Maurice Lenormand) en faveur du positionnement du parti pour l'indépendance. Ce parti sera, avec d'autres, fondateur du Front indépendantiste (FI) puis du Front de libération kanak et socialiste (FLNKS). 
Les années 1980 sont marquées en NouvelleCalédonie par une période d'insurrection et de lutte de libération nationale pour les Kanak, appelée communément «les Événements ", durant laquelle vont se produire de violents conflits. Auparavant, les indépendantistes kanak se sont regroupés en 1979 au sein du Front indépendantiste (FI), qui deviendra en 1984 le Front de libération nationale kanak et socialiste (FLNKS) (Leblic, 1993: 60-61). Le FLNKS est un mouvement de libération nationale rassemblant en son sein les différents partis politiques indépendantistes et, lors de sa création, d'autres mouvements tels que le GFKEL (Groupe des femmes kanak en lutte) ou le syndicat USTKE (Union des travailleurs kanak et exploités).

Durant toute cette période, et aujourd'hui encore, le FLNKS bénéficiait du soutien des États indépendants de la région et notamment à travers le Groupe mélanésien Fer de Lance ${ }^{13}$ et le Forum des Illes du Pacifique ${ }^{14}$, mais aussi au niveau international le Mouvement des NonAlignés ${ }^{15}$. Par ailleurs, l'affaire du Rainbow Warrior, en 1985, de même que les essais nucléaires en Polynésie française, avaient largement contribué à rendre la présence française quasi indésirable dans le Pacifique ${ }^{16}$.

\section{Autochtone et colonisé}

Grâce aux vagues mondiales d'accès à l'indépendance des pays et peuples colonisés, le droit international a permis la mise en œuvre d'un certain nombre de textes qui sont aujourd'hui devenus des outils juridiques à la disposition des peuples. Adoptés et/ou ratifiés par un État, ces textes peuvent permettre une reconnaissance effective d'un peuple autochtone et/ou colonisé qui vivrait sous la tutelle de l'État en question. Le peuple kanak, dans sa lutte pour l'indépendance, s'est servi et se sert d'un certain nombre de ces outils. Car, selon la jurisprudence internationale, le peuple kanak est à la fois autochtone et colonisé.

Ainsi, hier et aujourd'hui, les différents acteurs politiques en présence en NouvelleCalédonie (indépendantistes, mais aussi non indépendantistes, gouvernement, État français, etc.) s'approprient des normes existantes en matière de droits des peuples autochtones et de droits des pays et peuples coloniaux selon leurs objectifs propres. Mais de quelle manière le fontils? Et quelles sont les stratégies et politiques qu'ils mettent en œuvre pour répondre à leurs revendications et atteindre leurs objectifs? Parallèlement, quelles sont les stratégies politiques que l'État met en place pour assurer ses intérêts vis-à-vis de ces revendications ?

\section{L'inscription sur la liste des pays à décoloniser des Nations unies}

La première vague d'accès à l'indépendance des pays colonisés démarra immédiatement après la Deuxième Guerre mondiale (Chatenet, 1988 : 11-43). Ainsi, la Nouvelle-Calédonie fut inscrite une première fois sur la liste des pays à décoloniser des Nations unies en 1946 mais en fut retirée, à la demande de la France, dès l'année suivante, en 194717. En effet, comme

13. Le Groupe mélanésien Fer de Lance est l'organisation intergouvernementale des États indépendants de Mélanésie. Ses membres sont Fiji, le Vanuatu, la Papouasie Nouvelle-Guinée, les Îles Salomon et le FLNKs. Depuis sa création en 1988, le Groupe mélanésien Fer de Lance a toujours soutenu le FLNKS et le peuple kanak dans sa revendication d'indépendance et de décolonisation (http://www.msgsec.info/, consulté le 12/03/2012).

14. Le Forum des Îles du Pacifique a été fondé en août 1971 et est composé de seize membres : Australie, Îles Cook, États fédérés de Micronésie, Fiji, Kiribati, Nauru, Nouvelle-Zélande, Niue, Palau, Papouasie Nouvelle-Guinée, République des Îles Marshall, Samoa, Îles Salomon, Tonga, Tuvalu, Vanuatu. Le mandat du Forum des Îles du Pacifique est de renforcer l'intégration et la coopération régionale telles que définies dans le " Plan Pacifique ». Jusqu'en 2006, le FLNKS avait un statut d'observateur auprès du Forum des Îles du Pacifique. Depuis 2006, c'est la Nouvelle-Calédonie qui a le statut de membre associé du Forum. En 2011, le président du gouvernement de Nouvelle-Calédonie, Harold Martin, a demandé à en être membre à part entière (http://www.forumsec.org/, consulté le 12/03/2012).

15. Le Mouvement des Non-Alignés est un mouvement de 115 membres représentant « les intérêts et les priorités des pays en développement ». L'origine du mouvement date de la conférence de Bandung en 1955, en Indonésie. Durant cette réunion, les leaders des 29 États présents à l'époque se rendant compte qu'ils partageaient les mêmes problèmes décidèrent de s'allier pour « résister aux pressions des grandes puissances, maintenir leur indépendance et s'opposer au colonialisme et au néocolonialisme, spécialement à la domination occidentale. » (http://www.nam.gov.za/, consulté le 12/03/2012).

16. L'affaire du Rainbow Warrior, appelée aussi affaire Greenpeace, est un attentat commis par les services secrets français dans le port d'Auckland (Nouvelle-Zélande) le 10 juillet 1985, contre le bateau de Greenpeace, le Rainbow Warrior. Elle est liée

aux essais nucléaires effectués par la France dans le Pacifique (Polynésie française) car les écologistes de Greenpeace effectuaient des campagnes de protestation contre les essais nucléaires français, notamment à l'aide du navire Rainbow Warrior. Le photographe de Greenpeace, Fernando Pereira, fut tué dans l'attentat et le Rainbow Warrior coulé (Buso \& Choux, 2012 : 34).

17. Cet événement politique national et international de politique française fera l'objet d'un futur article dans lequel je le mettrai en parallèle avec la politique française mise en place à la même période en Nouvelle-Calédonie. 
nous l'explique Marie-Claude Smouts (1979: 217-218), avec la mise en place progressive au sein des Nations unies de mécanismes visant à éradiquer le colonialisme, en 1946, le Secrétaire général de l'Assemblée générale des Nations unies demanda aux puissances administrantes d'établir une liste des territoires non autonomes relevant de leur juridiction. La France fournit les noms des territoires suivants: Afrique équatoriale française, Afrique occidentale française, Côte française des Somalis, Établissement français de l'Inde, Établissements français d'Océanie, Guyane française, Guadeloupe et dépendances, Indochine, Madagascar et dépendances, Maroc, Martinique, Nouvelle-Calédonie et dépendances, Nouvelles-Hébrides sous condominium franco-britannique, La Réunion, SaintPierre-et-Miquelon, Tunisie. Mais, en 1947, la France prétexta que la «départementalisation de la Martinique, la Guadeloupe, la Guyane et la Réunion, l'assimilation juridique des populations de Nouvelle-Calédonie, d'Océanie et de Saint-Pierre-et-Miquelon, les libertés civiques et politiques conférées aux populations des Établissements français en Inde ne justifiaient plus le qualificatif «non autonome» attribué à ces territoires puisque leurs habitants jouissaient de droits comparables à ceux des citoyens de métropole $»^{18}$. En 1960, les Nations unies prirent acte des souhaits de nombreux peuples du monde d'accéder à l'indépendance et l'Assemblée générale des Nations unies adopta le 14 décembre 1960 la Déclaration sur l'octroi de l'indépendance aux pays et aux peuples coloniaux, connue aussi sous le nom de résolution 1514. Puis ils décidèrent de se doter d'un organe spécial qui serait chargé d'étudier l'application de la déclaration, faire des recommandations pour sa mise en œuvre, et de surveiller les processus de décolonisation à travers le monde. Il s'agit du Comité de décolonisation, ou Comité des 24, créé en 1961. Par ailleurs, la Quatrième commission de l'Assemblée générale des Nations unies est aussi en charge, entre autres, des questions de déco- lonisation. Celle-ci se réunit tous les mois d'octobre pour aborder ces questions en séances plénières. Le Comité de décolonisation, quant à lui, se réunit tous les mois de juin pour examiner de même la situation des seize territoires encore inscrits aujourd'hui sur la liste des pays à décoloniser ${ }^{19}$.

Grâce au travail de revendication des leaders indépendantistes kanak, et à la mobilisation du FLNKS auprès des Nations unies, et notamment auprès du Comité de décolonisation et de la Quatrième commission, la Nouvelle-Calédonie fut réinscrite sur la liste des pays à décoloniser le 2 décembre $1986^{20}$. Ainsi, l'Assemblée générale des Nations unies, lors de sa $48^{\mathrm{e}}$ session, adopta la résolution 41/41A dans laquelle elle considérait que :

" en vertu des dispositions du Chapitre XI de la Charte des Nations unies et des résolutions 1514 (XV) et 1541 (XV) de l'Assemblée générale, la NouvelleCalédonie est un territoire non autonome au sens de la Charte. » (ONU, A/AC.109/889)

Cette résolution affirme le droit inaliénable du peuple de Nouvelle-Calédonie à l'autodétermination et à l'indépendance.

D'autres faits ont permis de réinscrire la Nouvelle-Calédonie sur la liste des pays à décoloniser, notamment :

- le soutien des États de la région et d'institutions régionales et internationales comme le Groupe mélanésien Fer de Lance, le Forum des îles du Pacifique et le Mouvement des Non-Alignés;

- la reconnaissance informelle par l'onU du FLNKS comme représentant le peuple kanak dans un mouvement de libération nationale ;

- et les graves conflits qui secouaient le territoire durant les années 1980 et dont l'enjeu était justement la décolonisation et l'indépendance du pays et du peuple kanak colonisé.

C'est en effet le Forum du Pacifique qui avait proposé à l'Assemblée générale des Nations unies la réinscription de la Nouvelle-Calédonie

18. Voir aussi le Rapport de Victor Maamaatuaiahutaou, élu à l'assemblée de la Polynésie, sur la proposition de résolution du Président de l'assemblée appelant à la réinscription de la Polynésie sur la liste des pays à décoloniser à l'onU (http://madoynakupress.blogspot.com/2011/08/pour-la-reinscription-du-pays-maohi-sur.html, consulté le 07/03/2012). Il convient néanmoins de signaler ici qu'en 1958 il y eut la loi-cadre Deferre, suite à laquelle une partie de l'Outre-mer obtint le statut de territoire d'outre-mer (том), statut leur conférant plus d'autonomie vis-à-vis de la métropole. Ce point sera développé dans un futur article mentionné précédemment et qui portera sur l'inscription, la désinscription et la réinscription de la Nouvelle-Calédonie sur la liste des pays à décoloniser.

19. Il s'agit de la Nouvelle-Calédonie, Guam, Samoa américaines, Gibraltar, des Îles Malouines, Pitcairn, Antigua, des Îles Turques et Caïques, Anguilla, des Bermudes, Sainte-Hélène, des îles Vierges américaines, des îles Vierges britanniques, Montserrat, des îles Caïmans et du Sahara occidental. Mais pour ce dernier, seul le Conseil de sécurité des Nations unies a la charge de cette question du fait des graves conflits et violations des droits de l'homme qui s'y sont produits. De même, Tokelau est sur la liste des pays à décoloniser mais est susceptible d'en être retiré puisqu'en 2006 le non à l'indépendance l'a emporté au moment du référendum sur l'autodétermination. Tokelau est rattaché à la Nouvelle-Zélande.

20. Les positions de la France concernant la Nouvelle-Calédonie au sein des organes des Nations unies feront de même l'objet d'un futur article. 
sur la liste des pays à décoloniser. Lors de la réunion du Forum du 8 au 11 août 1986 à Suva, Fidji (ONU, A/AC.109/879), les chefs des États membres du Forum ont pris la décision de demander au Comité de décolonisation de réinscrire la Nouvelle-Calédonie sur la liste des territoires non autonomes, appelée aussi liste des pays à décoloniser. Lorsqu'ils se sont adressés au Comité de décolonisation, ils ont réaffirmé leur appui à une transition pacifique de la Nouvelle-Calédonie vers l'indépendance, qui soit conforme aux droits naturels et effectifs et aux aspirations de la population autochtone (ONU, A/AC.109/879, annexe II ).

Depuis cette date de 1986, le Comité de décolonisation surveille l'avancée du processus de décolonisation de la Nouvelle-Calédonie et la France doit régulièrement rendre des comptes, dans des rapports annuels qu'elle doit soumettre au Comité, ou lors des sessions du Comité et de la Quatrième commission. Des représentants d'ONG, du FLNKS, ou d'institutions de NouvelleCalédonie, mais aussi des représentants d'États voisins, peuvent de même soumettre leurs analyses et leurs revendications sur l'évolution du processus de décolonisation au Comité et à la Quatrième commission.

\section{La naissance du concept d' " autochtone " au sein} des Nations unies

Parallèlement, et une dizaine d'années après la création du Comité de décolonisation, s'est constitué au sein des Nations unies un mouvement qui allait travailler sur ce que sont aujourd'hui les droits des peuples autochtones. En effet, en 1977, à l'initiative de plusieurs mouvements et ONG amérindiens, une conférence internationale sur la « Discrimination à l'encontre des populations autochtones dans les Amériques » fut organisée au sein des Nations unies à Genève. C'est la première réunion onusienne durant laquelle la question autochtone est au cœur des discussions (Schulte-Tenckhoff, 1997 : 1-2). Puis, en 1981, une deuxième rencontre sur les questions des peuples autochtones, intitulée «Conférence internationale d'ONG sur les peuples autochtones et la terre » eut lieu aux Nations unies à Genève (Schulte-Tenckhoff, 1997 : 5). Suite à ces deux conférences, fut créé en 1982 un Groupe de travail sur les populations autochtones, rattaché à la Sous-commission de la lutte contre les mesures discriminatoires et de la protection des minorités, elle-même rattachée à la Commission des droits de l'Homme (Schulte-Tenckhoff, 1997 : 6). Un peu plus de dix ans plus tard, en 1995, l'Assemblée générale des Nations unies déclara 1995-2004 «Décennie internationale des populations autochtones » (Schulte-Tenckhoff, 1997 : 8).

En matière de définition de ce qu'est un «peuple autochtone », la référence au niveau des Nations unies est celle de José Martinez Cobo ${ }^{21}$ (Étude du problème de la discrimination à l'encontre des populations autochtones, E/CN.4/ Sub.2/1986/7). Selon lui, cette définition se base sur quatre critères qui sont :

- l'antériorité sur un territoire ;

- l'expérience du colonialisme ;

- la marginalisation vis-à-vis de la société dominante ;

- le souhait de maintenir une identité autochtone.

Ces quatre critères sont à la fois objectifs (origine commune, langue) et subjectifs (sentiment d'appartenance, identité) (ONU, 1996 : 9-10).

Le peuple kanak correspond précisément à cette définition de "peuples autochtones » de l'Organisation des Nations unies. Mais il faut néanmoins préciser ici que le peuple kanak s'est revendiqué en tant que tel dans une revendication politique d'indépendance face au colonisateur. Et c'est justement comme telle que se veut la définition de « peuples autochtones » au sein des Nations unies. Il ne s'agit pas d'une définition essentialiste de ce qu'est un peuple autochtone, mais bien d'une définition dans un contexte de revendications politiques et juridiques. De même, concernant le peuple autochtone de Nouvelle-Calédonie, donc le peuple kanak, du point de vue de l'organisation sociale, on parlera des sociétés kanak au pluriel et non pas d'une société kanak au singulier ${ }^{22}$. Par ailleurs, le terme « canaque » était au départ utilisé péjorativement par les colons pour parler des autochtones. Et c'est face aux allochtones que les Kanak ont ensuite revendiqué politiquement ce terme, avec son orthographe avec les deux $\mathrm{k}$, pour se nommer en tant que peuple uni et porteur d'un même désir d'indépendance.

La Déclaration sur les droits des peuples autochtones fut adoptée par l'Assemblée générale des Nations unies le 13 septembre 2007. S'ensuivirent la dissolution du Groupe de travail

21. Ce rapport et les recommandations qui y sont faites ont eu de même une forte influence sur la création, la structuration et la définition du mandat du Groupe de travail sur les Populations autochtones.

22. En effet, même s'il est possible de dire qu'il y a des points communs entre les sociétés kanak sur l'ensemble du territoire, il y a néanmoins de fortes différences dans l'organisation sociale, par exemple, que l'on soit à Tiga, à Ouvéa, à Gomen, ou ailleurs en Nouvelle-Calédonie. 


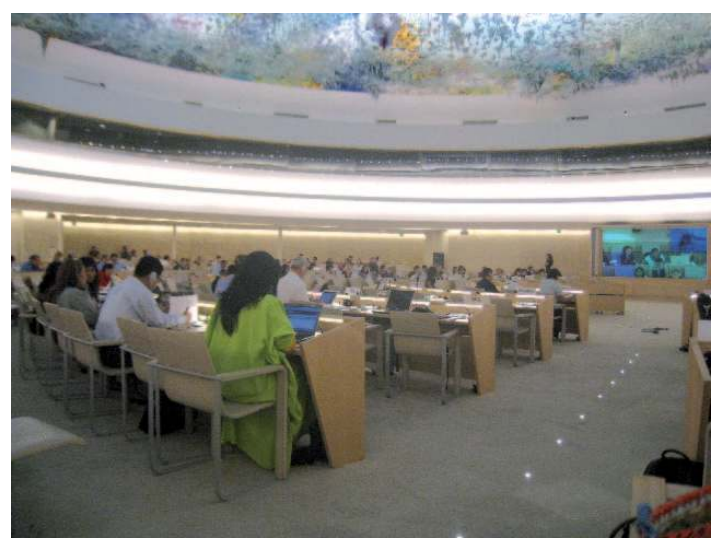

Pното 2. - Mécanisme d'Experts sur les droits des peuples autochtones, 12-16 juillet 2010, Nations unies, Genève (cliché de Roger Cho)

sur les populations autochtones et du Groupe de travail sur le projet de Déclaration des Nations unies sur les droits des populations autochtones et la création du Mécanisme d'Experts sur les droits des peuples autochtones ${ }^{23}$.

En outre, avant 2001, on ne note pas la présence régulière de délégations kanak lors des réunions onusiennes sur les droits des peuples autochtones. C'est seulement depuis 2001 que tous les ans, une ou plusieurs délégations de représentants kanak des milieux associatifs se rendent aux Nations unies à Genève, lors des sessions du Groupe de travail sur les populations autochtones. Alors pour quelles raisons, avant 2001, aucun intérêt particulier n'avait été manifesté par les Kanak pour ces réunions onusiennes?

Dans son article intitulé «Treaties, peoplehood and self-determination: understanding the language of Indigenous rights », Isabelle SchulteTenckhoff explique qu'en 1960, au moment de l'adoption de la résolution 1514, le discours du droit a limité l'application de la décolonisation pour les peuples autochtones en plaçant un certain nombre de limites. Celles-ci relèvent de ce qu'on a appelé en anglais The Salt Water Thesis, littéralement «la théorie de l'eau salée », et qui, toujours selon Isabelle Schulte-Tenckhoff, implique que seuls les territoires séparés par l'eau ou qui sont géographiquement séparés du pouvoir colonial peuvent invoquer l'autodétermination dans le sens de l'indépendance étatique
(2012 : 64-86). Ainsi, le peuple kanak, vivant sur un territoire ultra-marin au regard du pays qui le colonise, peut revendiquer l'autodétermination au sens d'indépendance étatique, ce qui explique aussi l'inscription de la Nouvelle-Calédonie sur la liste des pays à décoloniser.

Sachant, en outre, que des tentatives de revendication de souveraineté par des peuples autochtones devant les instances des Nations unies ${ }^{24}$ avaient déjà eu lieu avant la création des instances onusiennes de décolonisation et de droits des peuples autochtones, cette catégorisation des droits signifie-t-elle que les peuples autochtones sont ceux à qui les États ne voulaient pas permettre la décolonisation et l'indépendance ? Une nouvelle forme de décolonisation et d'autodétermination a-t-elle ainsi été créée pour eux afin qu'ils ne fassent pas sécession avec les États qui les colonisaient puisque géographiquement leurs territoires étaient englobés dans le territoire de l'État colonisateur?

\section{Jeux de mots et manipulation linguistique}

Qu'il s'agisse des droits des pays et peuples coloniaux à travers la Déclaration sur l'octroi de l'indépendance aux pays et peuples coloniaux, ou qu'il s'agisse des droits des peuples autochtones à travers la Déclaration des Nations unies sur les droits des peuples autochtones, tous deux ont comme clef de voûte le droit à l'autodétermination. Mais l'analyse de ce concept dans le contexte de chacune des deux déclarations montre que l'autodétermination n'y a pas les mêmes limites.

Dans la Déclaration des Nations unies sur les droits des peuples autochtones (2007), l'article 3 concerne le droit à l'autodétermination. Voici le contenu de cet article :

« Les peuples autochtones ont le droit à l'autodétermination. En vertu de ce droit, ils déterminent librement leur statut politique et assurent librement leur développement économique, social et culturel. » (ONU, A/RES/61/295 : 4)

Or, cet article ne peut pas être pris indépendamment de l'ensemble des articles contenus dans cette déclaration. Ainsi, l'article 46, alinéa 1, indique ce qui suit :

23. Le mandat du Mécanisme d'Experts sur les droits des peuples autochtones est un mandat de conseil fondé sur des études et des travaux notamment pour l'application effective de la Déclaration des Nations unies sur les droits des peuples autochtones.

24. Isabelle Schulte-Tenckhoff, dans son ouvrage La question des peuples autochtones relate qu'en 1923, « le chef iroquois Deskaheh se rend à la Société des Nations pour plaider la cause de son peuple en tant que nation souveraine » (1997:1). Il n'eut pas la possibilité d'entrer à la Société des Nations pour exposer la situation de son peuple. Il y eut une autre tentative d'entrée à la Société des Nations par des représentants amérindiens en 1930, qui se solda aussi par un échec. 


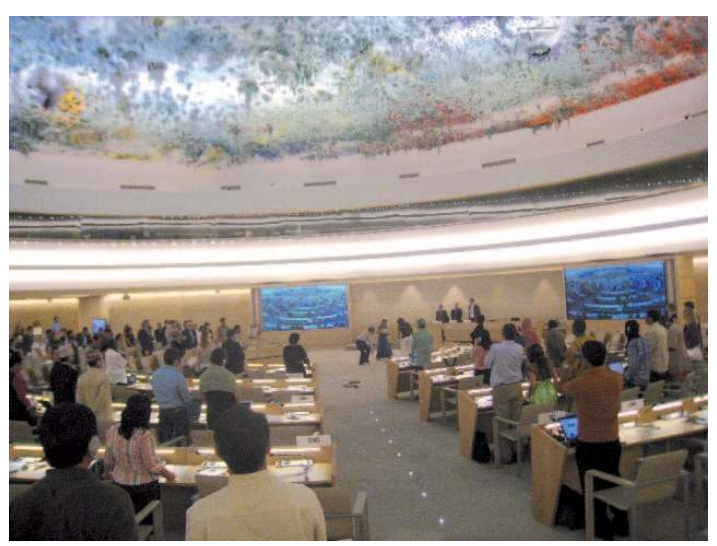

Рното 3. - Prière autochtone de clôture de session du Mécanisme d'Experts sur les droits des peuples autochtones, 16 juillet 2010, Nations unies, Genève (cliché de Roger Cho)

«Aucune disposition de la présente Déclaration ne peut être interprétée comme impliquant pour un État, un peuple, un groupement, ou un individu, un droit quelconque de se livrer à une activité ou d'accomplir un acte contraire à la Charte des Nations unies, ni considérée comme autorisant ou encourageant aucun acte ayant pour effet de détruire ou d'amoindrir, totalement ou partiellement, l'intégrité territoriale ou l'unité politique d'un État souverain et indépendant. » (ONU, A/RES/61/295 : 12)

Ainsi l'article 3 sur le droit à l'autodétermination trouve ses limites notamment dans l'article 46 de la Déclaration. Car si la déclaration ne doit pas porter atteinte à l'intégrité d'un État, en d'autres termes, nul peuple ou territoire ne peuvent en être séparés. De plus, l'article 4 de la Déclaration des droits des peuples autochtones parle bien d'autonomie interne :

"Les peuples autochtones, dans l'exercice de leur droit à l'autodétermination, ont le droit d'être autonomes et de s'administrer eux-mêmes pour tout ce qui touche à leurs affaires intérieures et locales, ainsi que de disposer des moyens de financer leurs activités autonomes. »

Tout ceci signifie donc que nous sommes dans un cadre d'《autodétermination interne » (Alfredsson, 1993 :42) puisque le peuple autochtone en question ne pourra avoir la possibilité de décider de se séparer de l'État dans lequel il est englobé et pourra s'autodéterminer uniquement pour tout ce qui concerne ses affaires internes. Dans son article intitulé "The right of selfdetermination and indigenous peoples », Gudmundur Alfredsson explique qu'elle en comporte deux types: l'autodétermination interne et l'autodétermination externe (Alfredsson, 1993 : 41-54). La première se réalise à l'intérieur d'un État et peut être plus ou moins large, c'est- à-dire que le peuple concerné peut avoir plus ou moins d'autonomie. Il y a donc différents degrés d'autodétermination interne qui dépendent du degré d'autonomie interne accordé par l'État souverain. Toujours d'après Alfredsson, aujourd'hui, seuls les États jouissent de l'autodétermination externe, c'est-à-dire celle qui permet non seulement la souveraineté interne, mais surtout celle qui autorise la prise de décisions et la souveraineté au niveau des relations externes avec les autres États et peuples, que ce soit la défense et l'armée, ou les relations économiques et commerciales, ou encore les relations internationales avec les autres États. Il n'y a donc pas, actuellement, d'autodétermination externe pour les peuples autochtones (Alfredsson, $1993: 50$ \& 54 ; voir aussi Schulte-Tenckhoff et Khan, $2011: 687)$.

Par ailleurs, nous sommes aussi, avec la Déclaration des Nations unies sur les droits des peuples autochtones, dans le cadre d'une autodétermination catégorisée et interprétée du domaine des droits de l'homme. C'est-à-dire, comme nous l'expliquent Isabelle Schulte-Tenckhoff et Adil Hasan Khan (2011: 673-701) qu'historiquement les mouvements revendicatifs des peuples autochtones ont été rattachés aux droits de l'homme réduisant ainsi ces revendications à des revendications de droits individuels plutôt que de droits des peuples.

Ainsi le peuple kanak autochtone et colonisé est dans le droit international concerné par plusieurs formes d'autodétermination, différentes les unes des autres. En effet, l'autodétermination dans les droits des peuples autochtones et celle dans les droits des pays et peuples coloniaux concernant la Nouvelle-Calédonie ne sont pas les mêmes. Dans les droits des peuples autochtones, il s'agit de l'autodétermination du peuple autochtone mais sous forme d'autonomie interne et interprétée au travers du prisme des droits de l'homme. Dans les résolutions adoptées aujourd'hui par le Comité de décolonisation des Nations unies et concernant la Nouvelle-Calédonie, l'autodétermination envisagée est une autodétermination à trois options pour l'ensemble du «territoire» de Nouvelle-Calédonie (ONU, A/AC.109/1049 \& A/RES/66/87), à savoir celles développées dans le principe VI de la résolution 1541 :

«On peut dire qu'un territoire non autonome a atteint la pleine autonomie : a) quand il est devenu État indépendant et souverain ; b) quand il s'est librement associé à un État indépendant ; ou c) quand il s'est intégré à un État indépendant. » (Document des Nations unies, Résolution 1541, Principes qui doivent guider les États membres pour déterminer si l'obligation 


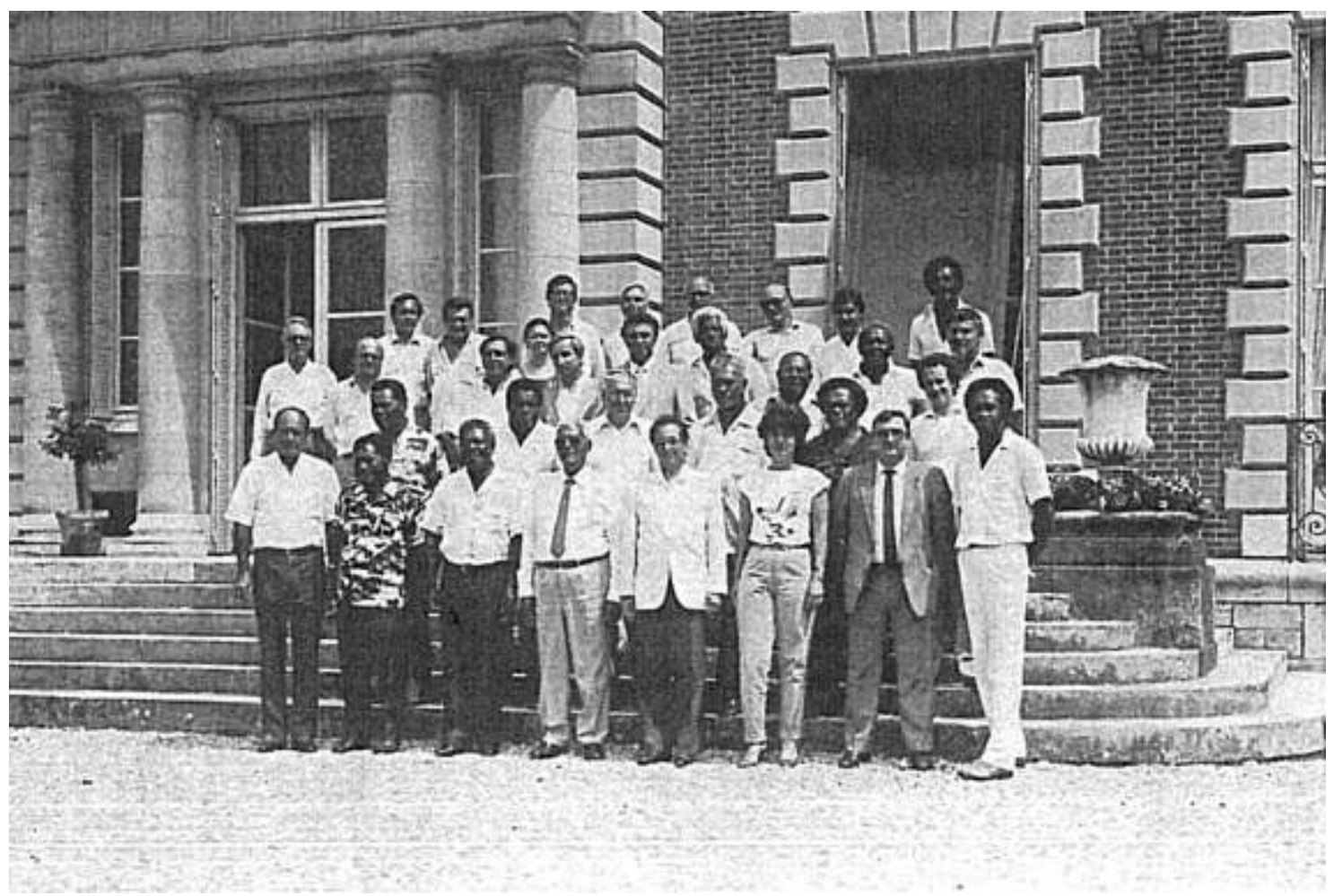

Рното 4. - Les participants à la table ronde de Nainville-les-Roches (C 5 jours à Nainville-les-Roches)

de communiquer des renseignements, prévue à l'alinéa e de l'article 73 de la Charte, leur est applicable ou non)

De fait, l'autodétermination pour la Nouvelle-Calédonie et le peuple kanak pourra prendre plusieurs « formes » :

- Indépendance totale,

- Indépendance-association (qui elle aussi peut s'appliquer sur différents « degrés » d'autodétermination),

- Souveraineté partagée,

- Autonomie interne (qui de même peut avoir différents « degrés »),

- Intégration dans la France,

- Ou autonomie plus ou moins développée et uniquement dans le cadre de l'autochtonie.

Il semble aussi important de préciser que la libre-association à un État indépendant ou l'intégration à un État indépendant peut être avec un État autre que celui qui était l'État colonisateur. Donc, une des options pour la Nouvelle-Calédonie pourrait tout à fait être aussi l'accession à l'indépendance puis la libreassociation avec un ou des États indépendants de la région de Mélanésie ou du Pacifique. Or, au niveau national et local des textes et accords politiques et juridiques qui concernent la Nouvelle-Calédonie, l'État a jusqu'à présent déjà délimité un cadre sur cette question d'autodétermination.

\section{L'autodétermination dans les accords de Nainville-les-Roches (1983)}

Concernant la question contemporaine de l'autodétermination, de l'indépendance et de l'autochtonie en Nouvelle-Calédonie, il est en effet primordial pour comprendre la position de la France, de même que la situation actuelle de la Nouvelle-Calédonie, de revenir sur la déclaration de la table ronde de Nainville-les-Roches qui s'est déroulée du 8 au 12 juillet 1983. Les négociations se sont effectuées entre les acteurs ci-après :

- pour les représentants du territoire: les conseillers territoriaux :

- le Rassemblement pour la Calédonie dans la République (RPCR) : Jean Lèques, Dick Ukeiwe, Victorin Boewa, Auguste Parawi-Reybas et Georges Faure ;

- la Fédération pour une nouvelle société calédonienne (FNSC) : Gaston Morlet, Christian Boissery ;

- le Front indépendantiste (FI) - Union calédonienne (UC) : Gabriel Paita, Éloi Machoro, Yeiwéné Yeiwéné, Édouard Wapae, Paul Naporea ;

- les parlementaires : Jacques Lafleur, Rock Pidjot, Lionel Cherrier ;

- le vice-président du Conseil du gouvernement : Jean-Marie Tjibaou ;

- le Président de l'Assemblée territoriale : JeanPierre Aifa ; 


\author{
- le Conseiller économique et social: André \\ Caillard ; \\ - le Conseil des grands chefs avec son représen- \\ tant Hilarion Vendegou et son secrétaire Franck \\ Wahuzue ; \\ - pour l'État: \\ - Marie-Paule Serve, conseillère territoriale \\ invitée par le secrétariat d'État ; \\ - les représentants du secrétariat d'État aux DOM- \\ том : le secrétaire d'État, Georges Lemoine ; le \\ directeur de Cabinet, Jacques Fournet; le \\ Conseiller technique, Jacques Ferstenbert; le \\ directeur de la DAPAF, Jean Montpezat ; le direc- \\ teur de la DAESC, Jean-Luc Mathieu; le haut- \\ commissaire de la Nouvelle-Calédonie, Jacques \\ Roynette ; le sous-directeur de la DAPAF, Ber- \\ nard De Gouttes ; et le conseiller d'État, Jean- \\ Claude Perrier.
}

On constate, dans la déclaration qui fut faite suite à ces journées de négociations, que les questions d'autodétermination, d'indépendance et d'autochtonie y ont déjà été cadrées. Voici l'article 1 de la déclaration :

« Volonté commune des participants de voir confirmer définitivement l'abolition du fait colonial par la reconnaissance à l'égalité de la civilisation mélanésienne et la manifestation de sa représentativité par la coutume dans les institutions à définir. » (Souligné par nous)

Dans cet article, l'abolition du fait colonial ne passe pas par l'indépendance du peuple colonisé, mais par la reconnaissance du fait que la civilisation de ce peuple colonisé est égale aux autres civilisations présentes en Nouvelle-Calédonie. De plus, la reconnaissance de l'autochtonie de cette civilisation serait traitée par l'État et se concrétiserait en créant des institutions « pour la coutume » qui, sont censées permettre une représentativité et une visibilité de cette civilisation dans l'ensemble des institutions du territoire. Ces institutions furent par la suite le Conseil consultatif coutumier (1988) puis le Sénat coutumier (1998). En d'autres termes, dans la déclaration de Nainville-les-Roches, abolir le fait colonial signifie reconnaître que la "civilisation mélanésienne » est égale aux autres civilisations et pour cela mettre en place des institutions "coutumières" afin de la rendre visible dans le paysage institutionnel du territoire ${ }^{25}$.

Poursuivons la lecture de la déclaration avec son article 2 qui traite aussi de l'autochtonie des Kanak et de la question de l'indépendance :
«Reconnaissance de la légitimité du peuple kanak premier occupant du territoire se voyant reconnaître en tant que tel un droit inné et actif à l'indépendance dont l'exercice doit se faire dans le cadre de l'autodétermination prévue et définie par la Constitution de la République française, autodétermination ouverte également pour des raisons historiques aux autres ethnies dont la légitimité est reconnue par les représentants du peuple kanak. » (Souligné par nous)

Il est très intéressant d'analyser ici ce qui est précisément reconnu au peuple kanak dans cet article. En premier lieu, on constate qu'il est écrit qu'il est le premier occupant du territoire. Mais ce qui lui est reconnu, en tant que premier occupant du territoire, c'est une légitimité de laquelle découle un droit à l'indépendance dans le cadre de l'autodétermination prévue par la Constitution française. En d'autres termes le peuple kanak a une légitimité à exercer une forme d'autodétermination que permet la Constitution française et qui, de plus, « est ouverte [...] pour des raisons historiques aux autres ethnies ». Pour les indépendantistes kanak, devoir exercer leur souhait d'autodétermination, c'est-à-dire l'indépendance dans le cadre de la Constitution française pose d'emblée un certain nombre de barrières. Tout d'abord, on bascule de la question de l'autodétermination du peuple kanak à celle de l'ensemble du territoire de Nouvelle-Calédonie puisque toute sa population est concernée, "pour des raisons historiques ». Mais aucune précision de dates n'a été donnée dans ce texte afin de définir qui sont ceux qualifiés de «victimes de l'histoire ${ }^{26}$. D'autre part, dans le préambule de la Constitution est évoquée la libre détermination des peuples qui est exercée notamment par voie référendaire. Ainsi, si la Constitution permet l'obtention de l'indépendance par voie référendaire, le résultat d'un éventuel référendum d'autodétermination dépendra bien entendu du corps électoral, donc de qui vote. La Constitution française étant basée sur le principe du suffrage universel donc un homme, une voix, cette proposition de l'État d'un exercice de l'autodétermination par le peuple kanak et les autres ethnies, "victimes de l'histoire », dans le cadre de la Constitution française peut poser un problème constitutionnel. Car si le corps électoral doit être restreint cette proposition est anticonstitutionnelle et si le corps électoral n'est pas restreint les indépendantistes sont perdants d'avance pour le vote de par la colonisation de peuplement qui les a rendus largement minoritaires.

25. Au sujet des statuts successifs, voir Leblic (1993: 53-74)

26. Ceux considérés comme étant les « victimes de l'histoire » sont notamment les descendants de bagnards. 
Ensuite, penchons-nous un instant sur l'intervention prononcée par le représentant de la France lors de l'adoption de la Déclaration sur les droits des peuples autochtones par l'Assemblée générale des Nations unies le 13 septembre 2007. Celui-ci dit la chose suivante :

«Pour la France, en vertu du principe d'indivisibilité de la République et conformément au principe fondamental d'égalité et de son corollaire, le principe de non discrimination, des droits collectifs ne peuvent prévaloir sur les droits individuels. Un traitement particulier peut cependant être accordé à des populations autochtones sur une base territoriale. Le droit à l'autodétermination, tout comme les consultations et referendums locaux, évoqués dans les articles $3,4^{27}$, [...] s'exercent conformément aux normes constitutionnelles nationales comme le prévoit l'article $46^{28}$ de la présente déclaration. [...]»

Ainsi, il est dit que la Constitution française basée sur le principe d'indivisibilité ne permet pas la reconnaissance de droits collectifs sur les droits individuels. De ce fait, si le peuple kanak dans la déclaration de Nainville-lesRoches est reconnu comme premier occupant de la Nouvelle-Calédonie, son autodétermination devant s'exercer dans le cadre de la Constitution française, celle-ci est une autodétermination interprétée sur la base de droits individuels et non de droits collectifs des peuples. Mais aussi le représentant de la France rappelle que le droit à l'autodétermination, de même que les consultations et référendum, doivent s'exercer dans le cadre des normes constitutionnelles comme le prévoit l'article 46 de la Déclaration sur les droits des peuples autochtones, qui, je le rappelle, place l'autodétermination dans le cadre d'une autonomie interne uniquement.

C'est cet article qui provoquera par la suite toute la polémique de la définition du corps électoral pour la consultation électorale sur l'accession à la pleine souveraineté à venir. Ainsi, toutes les barrières interprétatives de ce texte

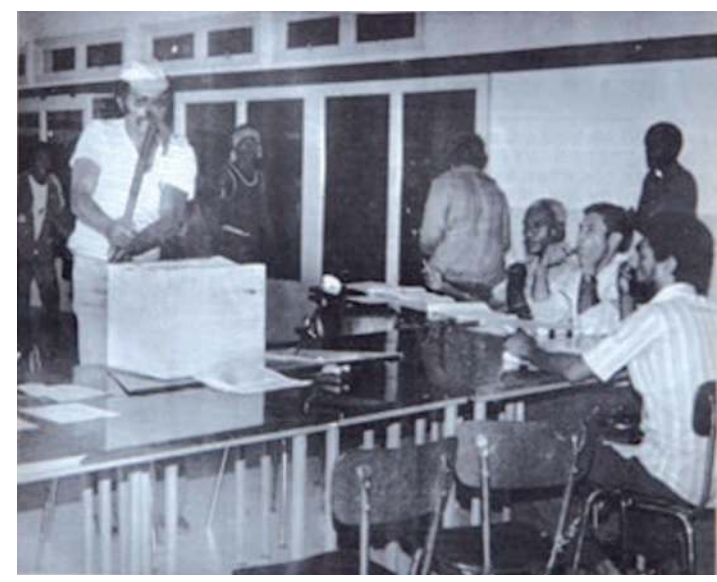

Рното 5. - Éloi Machoro brisant l'urne de vote à la mairie de Canala le 18 novembre 1984 dans le cadre du boycott actif $\mathrm{du}$ statut Lemoine (http://lecriducagou.com/?p=1545, consulté le 26/04/2012)

sont au cœur des conflits qui opposeront les indépendantistes à l'État. Comme l'explique Isabelle Leblic (1993 : 62), le statut Lemoine, qui représentait la mise en place effective de la déclaration de la table ronde de Nainville-les-Roches, « est à l'origine des événements de 1984 qui ont débuté par le boycott actif des élections du 18 novembre par les Kanak du FLNKS ». C'est ce jour qu'Éloi Machoro a déclenché l'insurrection de 1984 en brisant l'urne des votes à la mairie de Canala. Il le paya de sa vie puisqu'il fut assassiné, officiellement " neutralisé », par le GIGN, le 12 janvier 1985 ( $c f$. Entretiens avec Gabriel Païta, 2011). Revenons à notre déclaration. Dans l'article 3, l'État se place en accord avec les normes internationales et onusiennes puisqu'il est précisé ce qui suit :

« Favoriser l'exercice de l'autodétermination est "une des vocations de la France" qui doit permettre d'aboutir à un choix, y compris celui de l'indépendance. Il faut préparer cette démarche vers l'autodétermination qui sera le fait du peuple calédonien définie par la logique ci-dessus admise, lorsqu'il en sentira la nécessité. Pour

27. Article 3 de la Déclaration sur les droits des peuples autochtones : «Les peuples autochtones ont le droit à l'autodétermination. En vertu de ce droit, ils déterminent librement leur statut politique et assurent librement leur développement économique, social et culturel ». Article 4 de la Déclaration sur les droits des peuples autochtones : « Les peuples autochtones, dans l'exercice de leur droit à l'autodétermination, ont le droit d'être autonomes et de s'administrer eux-mêmes pour tout ce qui touche à leurs affaires intérieures et locales, ainsi que de disposer des moyens de financer leurs activités autonomes ».

28. Article 46 de la Déclaration sur les droits des peuples autochtones : « 1 . Aucune disposition de la présente Déclaration ne peut être interprétée comme impliquant pour un État, un peuple, un groupement ou un individu un droit quelconque de se livrer à une activité ou d'accomplir un acte contraire à la Charte des Nations Unies, ni considérée comme autorisant ou encourageant aucun acte ayant pour effet de détruire ou d'amoindrir, totalement ou partiellement, l'intégrité territoriale ou l'unité politique d'un État souverain et indépendant. 2. Dans l'exercice des droits énoncés dans la présente Déclaration, les droits de l'homme et les libertés fondamentales de tous sont respectés. L'exercice des droits énoncés dans la présente Déclaration est soumis uniquement aux restrictions prévues par la loi et conformes aux obligations internationales relatives aux droits de l'homme. Toute restriction de cette nature sera non discriminatoire et strictement nécessaire à seule fin d'assurer la reconnaissance et le respect des droits et libertés d'autrui et de satisfaire aux justes exigences qui s'imposent dans une société démocratique. 3 . Les dispositions énoncées dans la présente Déclaration seront interprétées conformément aux principes de justice, de démocratie, de respect des droits de l'homme, d'égalité, de non-discrimination, de bonne gouvernance et de bonne foi. » 


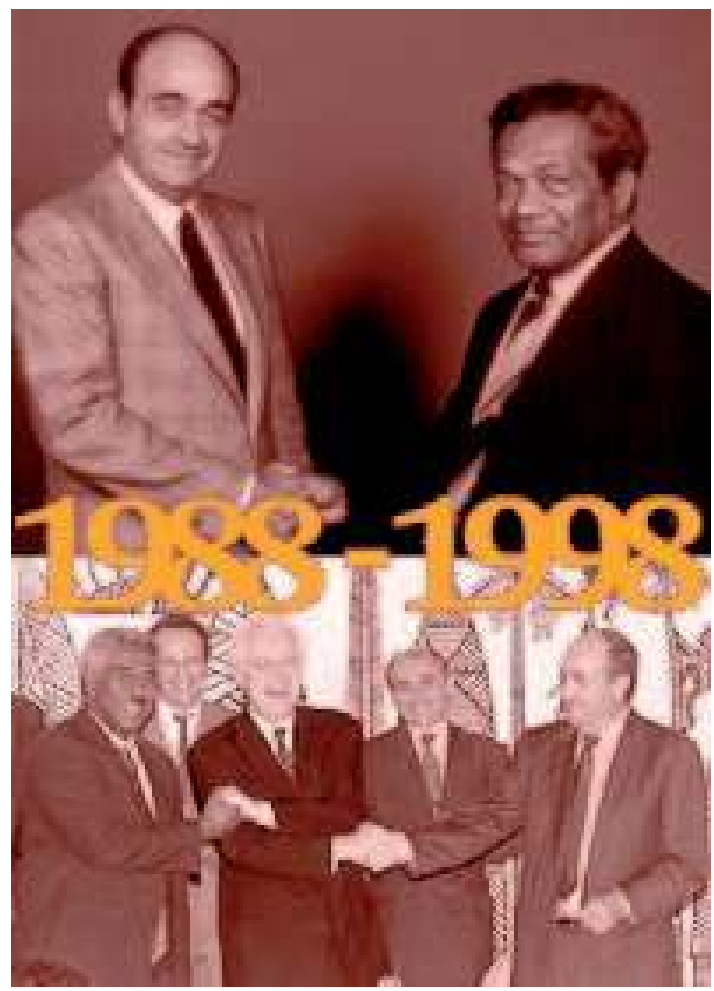

Document 1. - En haut : Poignée de mains entre Jean-Marie Tjibaou et Jacques Lafleur suite à la signature des accords de Matignon; en bas : Poignée de mains entre Rock Wamytan, Lionel Jospin et Jacques Lafleur suite à la signature de l'accord de Nouméa http://www.2011-anneedes-outre-mer.gouv.fr/themes/colloque/363/des-accordsde-matignon-a-laccord-de-noumea-et-apres.html, consulté le 26/04/2012)

préparer cette démarche, chacun est conscient qu'il faut élaborer un statut d'autonomie interne qui sera spécifique, qui sera évolutif et qui marquera donc une phase de transition en prenant en compte les données politiques et économiques car il n'y aura de développement économique qu'avec la stabilité politique. » (Souligné par nous)

Lors du vote sur l'autodétermination, il est dit ici que les électeurs auront donc, entre autres, le choix de l'indépendance. Ensuite, il est précisé que le choix de l'autodétermination sera le fait du peuple calédonien. Ainsi, l'autodétermination ne concerne plus le seul peuple colonisé mais les autres populations aussi. Nous verrons par la suite que les résolutions des Nations unies sur la décolonisation et concernant la NouvelleCalédonie ont suivi cette argumentation dans la terminologie utilisée.

La déclaration de la table ronde de Nainvilleles-Roches constitue les prémisses de tous les accords qui ont suivi, c'est-à-dire les accords de Matignon-Oudinot (1988) et l'accord de Nouméa (1998) (voir entre autres Leblic, 1993 : 53-59 ; 2003a : 138 et 2007 : 279-280). Cette déclaration a dressé le cadre politique et institutionnel de la Nouvelle-Calédonie d'aujourd'hui. On y voit même dans l'expression « peuple calédonien » ce qui est aujourd'hui la citoyenneté calédonienne définie par le corps électoral restreint dont les prémisses sont aussi dans cette même déclaration.

La déclaration de Nainville-les-Roches a recueilli l'accord de la FNSC, du Front indépendantiste et fait l'objet de réserves du $\mathrm{RPCR}^{29}$.

\section{De Matignon à Nouméa}

Après la période dite des «Événements » et suite au drame d'Ouvéa (avril-mai 1988) ont été signés les accords de Matignon en $1988^{30}$, puis l'accord de Nouméa en $1998^{31}$ qui poursuivent ce qui a été mis en place à Nainville-les-Roches au sujet de l'autodétermination, de la décolonisation et de l'autochtonie. En effet, comme il a été vu précédemment, la déclaration de Nainville-les-Roches prévoyait « la manifestation de [1]a représentativité [de la « civilisation mélanésienne »] par la coutume dans les institutions à définir ». Ainsi fut créé, à travers les accords de Matignon, le Conseil consultatif cou-

29. Mais il est dit que si, officiellement, la déclaration de Nainville-les-Roches a été acceptée de tous, le leader indépendantiste, Éloi Machoro aurait fortement manifesté son désaccord avec les propositions de l'État car il considérait que cette déclaration ne reconnaissait en rien le droit du peuple kanak, seul peuple colonisé de Nouvelle-Calédonie, à l'indépendance et que, de plus, aucune garantie d'indépendance n'apparaissait dans cette déclaration.

30. Les accords de Matignon-Oudinot ont été signés le 26 juin (accord de Matignon) et le 20 août (accord d'Oudinot) 1988 entre le FLNKS, le RPCR et l'État français. Son application juridico-légale est mise en place par la loi référendaire $n^{\circ} 88-1028$ du 8 novembre 1988 portant dispositions statutaires et préparatoires à l'autodétermination de la Nouvelle-Calédonie en 1998.

31. L'accord de Nouméa a été signé le 5 mai 1998 entre le FLNKs, le RPCR et l'État français. Son application juridico-légale est définie par la loi no 99-209 du 19 mars 1999 organique relative à la Nouvelle-Calédonie. Il est considéré comme mettant en place un processus de décolonisation progressive, surtout du fait qu'il est censé rendre effectif un transfert progressif et irréversible des compétences de l'État au territoire de Nouvelle-Calédonie et à ses institutions. La consultation électorale prévue entre 2014 et 2018 sur l'accession à la pleine souveraineté doit porter sur le transfert des compétences régaliennes. L'accord de Nouméa a nécessité d'être intégré à la Constitution française, car dépassant les limites d'autonomie interne d'un territoire français fixée par le cadre de la République. 
tumier, et le pays fut divisé en huit aires coutumières $^{32}$. Suite à l'accord de Nouméa signé le 5 mai 1998, le Conseil consultatif coutumier a été transformé en Sénat coutumier. Le rôle du Sénat coutumier est consultatif. Le Congrès de Nouvelle-Calédonie doit solliciter son avis pour toutes les « lois du pays » qui ont trait à l'identité kanak et aux terres coutumières.

Concernant la question de l'autodétermination, les accords de Matignon prévoyaient un scrutin en 1998 et avait fondé le corps électoral pour ce scrutin sur ce qui avait déjà été avancé au moment de Nainville-les-Roches. Toutefois le corps électoral pour ce référendum n'a pas été arrêté aux seules " victimes de l'histoire », que le FI avait accepté d'intégrer, mais a été élargi à ceux installés en Nouvelle-Calédonie jusqu'à la date du référendum ayant approuvé les accords de Matignon, c'est-à-dire le 6 novembre 1988, comme l'indique l'article 2 de la loi référendaire $\mathrm{n}^{\circ} 88-1028 \mathrm{du} 9$ novembre 1988 portant dispositions statutaires et préparatoires à l'autodétermination de la Nouvelle-Calédonie en 1998 :

«[e]ntre le $1^{\text {er }}$ mars et le 31 décembre 1998, les populations intéressées de la Nouvelle-Calédonie seront appelées à se prononcer par un scrutin d'autodétermination, conformément aux dispositions de l'article 53 de la Constitution, sur le maintien du territoire dans la République ou sur son accession à l'indépendance. Seront admis à participer à ce scrutin les électeurs inscrits sur les listes électorales du territoire à la date de cette consultation et qui y ont leur domicile depuis la date du référendum approuvant la présente loi. Sont réputées avoir leur domicile dans le territoire, alors même qu'elles accomplissent le service national ou poursuivent un cycle d'études ou de formation continue hors du territoire, les personnes qui avaient antérieurement leur domicile dans le territoire. »
Finalement, comme nous le savons, le scrutin d'autodétermination n'a pas été effectué en 1998 car un nouvel accord a été signé, l'accord de Nouméa, qui, comme dit précédemment, prévoit la consultation électorale sur l'accession à la pleine souveraineté entre 2014 et $2018^{33}$.

\section{Les accords ont-ils eu une influence sur les résolu- tions des Nations unies?}

Concernant l'évolution des textes et résolutions du Comité de décolonisation et de la Quatrième Commission de l'Assemblée générale des Nations unies, on constate, depuis la signature des accords de Matignon, un changement de terminologie concernant la NouvelleCalédonie $^{34}$. Ce changement est très probablement dû au choix d'un certain type de processus de décolonisation, par les acteurs locaux de Nouvelle-Calédonie et l'État, engagé depuis Nainville-les-Roches, mais devenu force de loi depuis les accords de Matignon, puis l'accord de Nouméa. En effet, entre la réinscription de la Nouvelle-Calédonie sur la liste des pays à décoloniser le 2 décembre 1986 et la signature des accords de Matignon le 26 juin 1988, les résolutions adoptées par les Nations unies se réfèrent au droit inaliénable du peuple de NouvelleCalédonie (ou du peuple néo-calédonien) à l'autodétermination et à l'indépendance (ONU, Résolution 41/41A du 2 décembre 1986 \& résolution 42/79 du 4 décembre 1987 \& A/AC.109/931). Tout de suite après la signature des accords de Matignon, la résolution adoptée par l'Assemblée générale des Nations unies concernant la décolonisation de la NouvelleCalédonie, datant du 10 août 1988, fait disparaître le mot « indépendance » pour laisser uniquement celui d'« autodétermination ». De même,

32. Les huit aires coutumières sont les suivantes : Djubea Kapone, Xaracuu, Ajie Aro, Paici Camuki, Hoot ma Waap, Iaai, Drehu, Nengone.

33. Après de nombreux conflits politiques, le corps électoral pour la consultation sur l'accession à la pleine souveraineté a finalement été figé à ce qui suit, tel qu'indiqué dans l'article 218 de la loi organique faisant suite à l'accord de Nouméa : "Sont admis à participer à la consultation les électeurs inscrits sur la liste électorale à la date de celle-ci et qui remplissent l'une des conditions suivantes : a) Avoir été admis à participer à la consultation du 8 novembre 1998 ; b) N'étant pas inscrits sur la liste électorale pour la consultation du 8 novembre 1998, remplir néanmoins la condition de domicile requise pour être électeur à cette consultation ; c) N'ayant pas pu être inscrits sur la liste électorale de la consultation du 8 novembre 1998 en raison du non-respect de la condition de domicile, justifier que leur absence était due à des raisons familiales, professionnelles ou médicales ; d) Avoir eu le statut civil coutumier ou, nés en Nouvelle-Calédonie, y avoir eu le centre de leurs intérêts matériels et moraux ; e) Avoir l'un de leurs parents né en Nouvelle-Calédonie et y avoir le centre de leurs intérêts matériels et moraux ; f) Pouvoir justifier d'une durée de vingt ans de domicile continu en Nouvelle-Calédonie à la date de la consultation et au plus tard

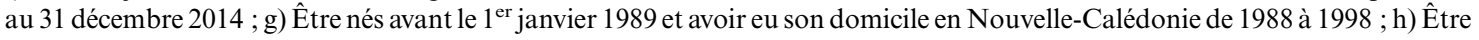
nés à compter du $1^{\mathrm{er}}$ janvier 1989 et avoir atteint l'âge de la majorité à la date de la consultation et avoir eu un de leurs parents qui satisfaisait aux conditions pour participer à la consultation du 8 novembre 1998. Les périodes passées en dehors de la Nouvelle-Calédonie pour accomplir le service national, pour suivre des études ou une formation ou pour des raisons familiales, professionnelles ou médicales ne sont pas, pour les personnes qui y étaient antérieurement domiciliées, interruptives du délai pris en considération pour apprécier la condition de domicile. »

34. Cette analyse de ce changement de terminologie dans les résolutions des Nations unies sur la décolonisation de la Nouvelle-Calédonie fera ultérieurement l'objet d'un article plus détaillé. 
le « peuple de Nouvelle-Calédonie » ou « peuple néo-calédonien » est remplacé par «les habitants de Nouvelle-Calédonie » ou les « NéoCalédoniens » (ONU, Résolution du 10 août 1988 in A/AC.109/971). Toutes les résolutions suivantes adopteront cette terminologie (ONU, Résolution 43/34 du 22 novembre 1988; A/AC.109/1012; résolution 44/89 du 11 décembre 1989; résolution 45/22 du 20 novembre 1990 ; etc.). Aujourd'hui, en 2012, on parle dans ces résolutions d'« autodétermination du territoire " (ONU, A/RES/66/87). Ainsi, de " peuple », il n'est plus question que des « habitants de... » ou « les Néo-Calédoniens », pour arriver à la notion de « territoire ». De même, «l'autodétermination et l'indépendance » sont devenues « autodétermination ». De l'autodétermination et l'indépendance d'un peuple, on est passé à l'autodétermination d'un territoire.

Pourquoi ce changement ? Il convient de rappeler que le rôle des Nations unies, dans quelque domaine que ce soit, a des limites. L'une d'elles s'appelle d'ailleurs la non-ingérence. Si les Nations unies, dans leur programme et les " décennies » qu'ils mettent en place, cherchent à lutter contre le colonialisme, ses actions ne peuvent dépasser un certain stade. Que ce soit à Nainville-les-Roches, dans les accords de Matignon-Oudinot, ou celui de Nouméa, nous sommes dans le cadre d'un accord interne à la France, même s'il est surveillé par l'international. Les Nations unies ont adapté leur terminologie à ce qui a été signé entre les différents protagonistes locaux.

Les accords poussent-ils les Kanak vers des revendications de droits des peuples autochtones?

Une des hypothèses que j'émets est que la mise en place des stratégies politiques de la France, depuis Nainville-les-Roches, a eu pour conséquence, notamment, de voir émerger des mouvements associatifs kanak ayant choisi la voie des droits des peuples autochtones. En effet, si aucun représentant kanak, politique et associatif confondus, n'était présent lors des réunions onusiennes sur ces questions avant l'accord de Nouméa, des représentants kanak de mouve-

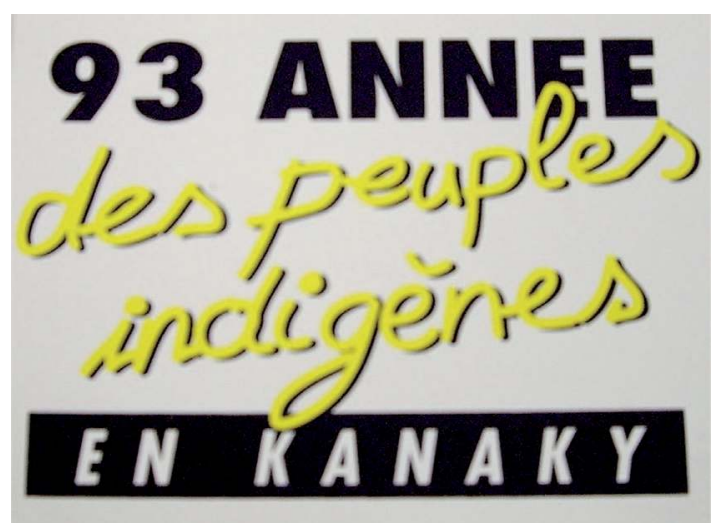

Document 2. - Tract autocollant pour la promotion de l'Année des peuples indigènes en Kanaky (1993)

ments associatifs le furent après. Et, par ailleurs, on constate sur les choix de stratégies, une division des indépendantistes kanak après 1988. En interne, un virage vers l'usage et la mise en avant plus concrète des droits des peuples autochtones a été pris peu de temps après les accords de Matignon par certains militants du FLNKS. En 1993 a été créé l'ACAPIK ${ }^{35}$, l'Association pour la célébration de l'année du peuple indigène en Kanaky, qui est ensuite devenue en 1995 le $\mathrm{CNDPA}^{36}$, Conseil national des droits du peuple autochtone (Monnerie, 2005: 20; Demmer, 2007) et qui coïncide avec la proclamation par l'Assemblée générale des Nations unies (1993) de la Décennie internationale des peuples autochtones (1995-2004). Comme le dit Denis Monnerie dans son ouvrage La parole de notre Maison :

«À partir de 1993, la plupart des mouvements indépendantistes se sont retrouvés dans des associations larges, ouvertes aux non indépendantistes (et aux non Kanak). [...] La première de ces formations fut l'Association pour la célébration de l'année des peuples indigènes de Kanaky, ACAPIK, fondée en 1993. La même année celle-ci a coordonné pour l'ensemble du pays, une grande part de l'organisation des cérémonies de l'Année internationale des peuples indigènes qui devait culminer le 24 septembre à Poindimié. Puis le Conseil national pour les droits du peuple autochtone, CNDPA, a pris le relais et organisé de grandes cérémonies en septembre 1997 à Lifou (à une date proche du 24 septembre). L'impulsion donnée par l'onU a été cruciale, y compris dans le changement de vocabulaire, puisque en 1993 et en 1997 ces célébrations ont

35. L'objectif de départ de l'ACAPIK était d'organiser chaque année la commémoration de « deuil kanak » de la prise de possession du 24 septembre 1853 et de traduire en Nouvelle-Calédonie le projet de la décennie sur les droits des peuples autochtones (entretiens réalisés en Nouvelle-Calédonie en 2010 avec Thierry Kameremoin, Raphaël Mapou, et le pasteur Passa Sailali).

36. Le CNDPA est, selon ses statuts, une organisation non gouvernementale qui se compose de représentants des instances traditionnelles coutumières kanak, des représentants des organisations syndicales, des organisations religieuses, ainsi que d'associations. Le but du CNDPA est de défendre l'ensemble des droits du peuple kanak - droit à la terre, droit à l'autodétermination, droits collectifs et individuels, et droits culturels et intellectuels - en tant que peuple autochtone de Nouvelle-Calédonie (entretiens réalisés en Nouvelle-Calédonie en 2010 avec le pasteur Passa Sailali et Dick Saihu). 
concerné respectivement les années internationales des "peuples indigènes" puis des "peuples autochtones". Les droits imprescriptibles des Kanak sur leur pays et l'aspect culturel de leurs revendications sont mis en avant, d'abord autour de l'idée de "peuple indigène" puis de celle de "peuple autochtone".» (Monnerie, $2005: 20$ )

Parallèlement, en 1992, le parti politique FULK fut dissous et, le 24 septembre de la même année, fut créé le Congrès populaire, ONG qui explique avoir pour fondement la coutume et qui s'inscrit dans l'esprit de la Déclaration des droits des peuples autochtones, principalement sur le droit à la terre, le droit à l'autodétermination et le droit à l'éducation du peuple kanak ${ }^{37}$.

C'est ensuite vers le début des années 2000 que se sont rendus régulièrement, des représentants d'oNG kanak dans les réunions des Nations unies sur les droits des peuples autochtones. Il s'agissait principalement de représentants des CNDPA ${ }^{38}$ et du Congrès populaire puis, par la suite, du comité Rheebu $\mathrm{Nuu}^{39}$ et du Sénat coutumier.

Mais pourquoi un tel changement de choix de stratégie ? Rappelons la Salt Water Thesis qui dit que seuls les territoires séparés par l'eau ou qui sont géographiquement séparés du pouvoir colonial peuvent invoquer l'autodétermination dans le sens de l'indépendance étatique (SchulteTenckhoff, 2012 : 64-86). Une de mes hypothèses à propos de la non-présence des Kanak, avant 2000, dans les réunions onusiennes sur les droits des peuples autochtones est peut-être qu'avant 1988 et la signature des accords de Matignon, la lutte des indépendantistes kanak se place effectivement dans une même stratégie de lutte pour l'indépendance dont l'objectif est de devenir un État souverain. Or, les normes juridiques des droits des peuples autochtones tels qu'adoptés aujourd'hui ne permettent pas pour un peuple autochtone la séparation d'avec l'État dominant mais impliquent plutôt le respect d'un mode de vie et une forme plus ou moins poussée d'autonomie dans l'État dominant. Sachant que le peuple kanak (en grande partie mais il y a aussi des
Kanak contre l'indépendance) revendique son indépendance étatique et de fait celle de son pays, et que la Nouvelle-Calédonie est inscrite sur la liste des pays à décoloniser, l'outil onusien du droit des peuples autochtones devrait présenter peu d'intérêt pour lui puisque cet outil ne lui permet pas de se décoloniser dans le sens de devenir indépendant vis-à-vis de la France ${ }^{40}$. Pourtant, les leaders kanak des mouvements associatifs qui utilisent les droits des peuples autochtones aujourd'hui affirment bien être toujours indépendantistes. La voie des accords est pour les leaders indépendantistes kanak la voie difficile de la tentative d'accession à l'indépendance par les institutions et le vote électoral.

Il est vraisemblable que cette voie des accords avec l'obtention de l'indépendance par les urnes ne garantit pas le résultat escompté pour beaucoup de militants indépendantistes kanak qui ont cherché une autre voie possible que celle de la politique. Mais aussi, comme le montrent les changements de terminologie dans les résolutions onusiennes, et comme le prouvent les différents accords signés depuis la déclaration de Nainville-les-Roches, la question de l'autodétermination n'est plus aujourd'hui celle du peuple kanak mais bien celle de la Nouvelle-Calédonie et de ses habitants pris en compte dans le corps électoral restreint. De fait, la question de la souveraineté des Kanak dans le pays se pose toujours, que le pays soit indépendant ou non.

Ainsi, dans l'attente d'une indépendance qui tarde de plus en plus, certains auraient-ils décidé d'utiliser un outil qui leur permettrait de sauvegarder leur mode de vie en interne, c'est-à-dire dans la France? Ou peut-être de peur de se retrouver dans un pays indépendant aux mains de la population d'ascendance européenne, certains militants kanak ont-ils décidé de choisir une voie qui leur donnait l'impression de pouvoir garantir leur mode de vie tout en leur permettant une certaine forme d' « autonomie autochtone » sur des territoires définis à l'intérieur de l'État actuel ou de celui de demain ? Ou bien, pour d'autres, le choix de la stratégie des droits des peuples autochtones montrerait-il un

37. Entretiens avec Cho Roger, réalisés en Nouvelle-Calédonie en 2010, et enregistrement d'un discours de Yann Céléné Uregei pour le Congrès populaire aux Nations unies à New York.

38. Les membres du CNDPA se sont divisés entre eux mais ont continué chacun de leur côté le travail du CNDPA. Aux alentours de 2007 on comptait trois CNDPA, un CNDPA rattaché au sénat coutumier, un comité de coordination CNDPA et un CNDPA Lifou.

39. Le comité Rheebu Nuu a été créé en 2002 pour contrer le projet Goro-Nickel de construction de l'usine d'exploitation de nickel dans le Sud de la Nouvelle-Calédonie. Suite à un accord signé avec l'industriel en 2009, les activités du comité ont été ralenties.

40. D'ailleurs dans le projet de constitution de Kanaky, établi par le FLNKs et déposé aux Nations unies à New York en janvier 1987, il n'est pas fait mention du terme « autochtone ». Il est dit néanmoins dans le préambule que « le Clan [...] est le détenteur traditionnel de la terre selon les règles coutumières dans le respect des intérêts de la collectivité nationale ». De plus, l'article 1 définit le peuple kanak comme suit : «Le peuple kanak constitue une communauté nationale et pluriethnique, libre, unie et souveraine, fondée sur la solidarité de ses divers éléments. La République Kanak est une république démocratique, laïque et socialiste. ». 


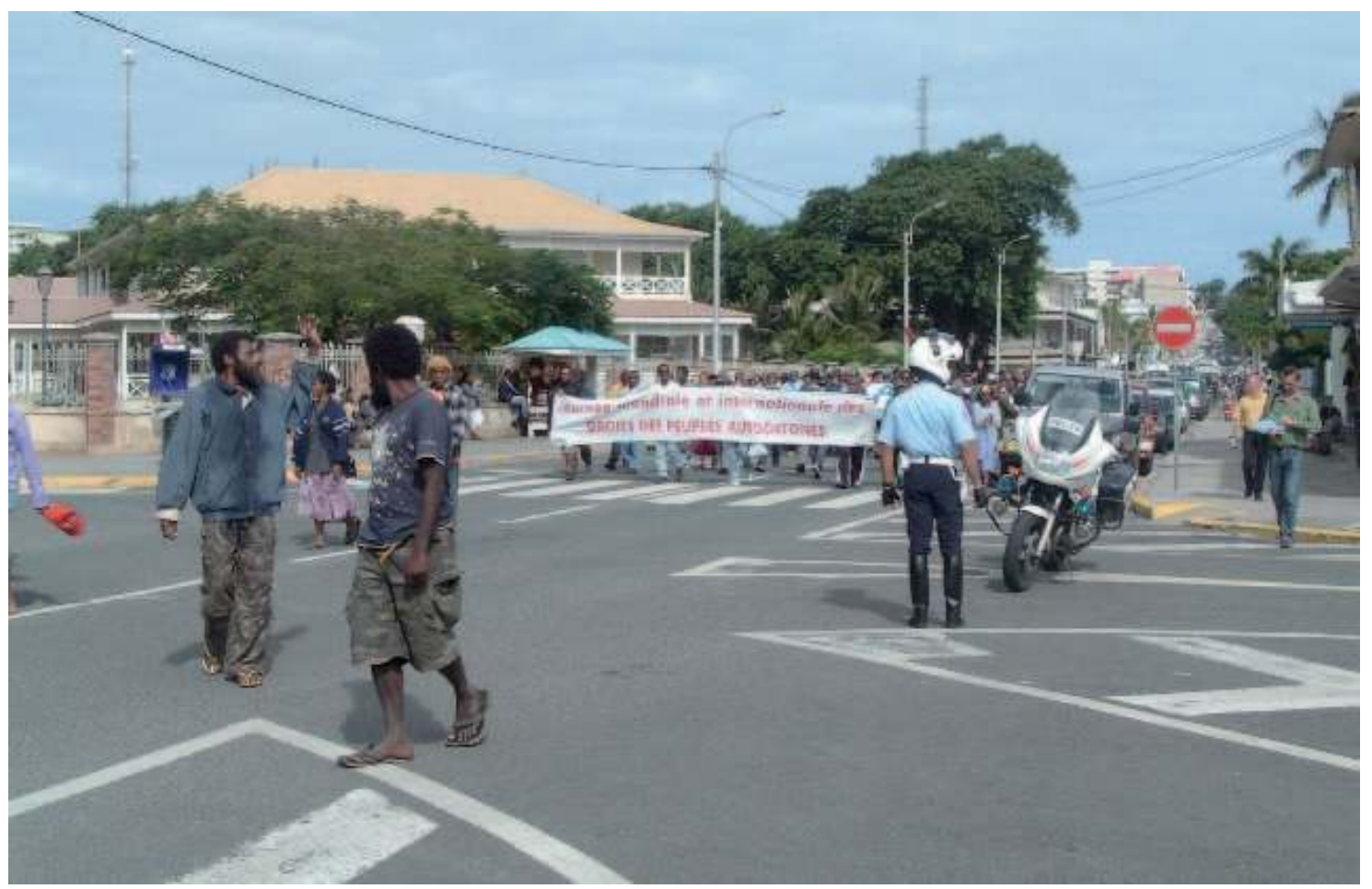

Рното 6. - L'Assemblée générale des Nations unies a décrété en 1994 le 9 août Journée internationales des peuples autochtones : marche pour cette journée à Nouméa le 9 août 2007 (cliché de l'auteur)

changement de position inavoué vis-à-vis de l'indépendance?

Comme le dit Benoît Trépied, il y a aujourd'hui ceux qui estiment que les accords, notamment l'accord de Nouméa, ont reconnu le principe des droits des Kanak et ceux qui revendiquent « de nouvelles garanties légales, politiques et financières pour que les droits du peuple kanak soient respectés dans la société calédonienne, [...] et quelle que soit l'évolution statutaire du pays » (http://www.sogip.ehess. fr/spip.php?rubrique48, consulté le 15/03/2012) à travers l'outil des droits des peuples autochtones. J'ai montré que cette division n'est pas récente. Elle se manifeste institutionnellement avec la création de l'ACAPIK et date de 1 '« après-Matignon ».

Ces dix dernières années, les leaders kanak sont mêmes beaucoup plus présents au niveau des institutions internationales traitant des droits des peuples autochtones que de celles traitant des droits des pays et peuples coloniaux. Hormis l'année 2001, 2005 et 2008 où Rock Wamytan $^{41}$, signataire FLNKS de l'accord de Nouméa et à l'époque conseiller spécial auprès de la présidence du sénat coutumier, et Julien
Boanemoi (en 2008), à l'époque sénateur coutumier de l'aire ajië-arö, ont effectué un discours devant la Quatrième commission de l'Assemblée générale des Nations unies sur les questions de politiques spéciales et la décolonisation, les autres années les représentants politiques Kanak indépendantistes, comme les politiques non indépendantistes, n'étaient pas présents aux sessions du Comité de décolonisation et de la Quatrième commission ${ }^{42}$. Pourtant, de la fin des années 1970 jusqu'au début des années 1990, leur présence à ces sessions était nettement plus assidue. Aujourd'hui nous sommes dans la dernière mandature avant celle durant laquelle se déroulera la consultation électorale sur l'accession du territoire à la pleine souveraineté, et l'intérêt pour les questions de décolonisation aux Nations unies paraît reprendre de la vigueur. Ainsi, en octobre 2009, lors de la $64^{\mathrm{e}}$ session de la Quatrième commission relative aux questions de décolonisation des Nations unies, à New York, une délégation du gouvernement de NouvelleCalédonie, menée par son président Philippe Gomès, a prononcé un discours et invité le Comité de décolonisation à organiser son pro-

41. Il avait néanmoins envoyé plusieurs dossiers au Comité de décolonisation par courrier et avait fait des demandes pour qu'une mission du Comité de décolonisation soit organisée en Nouvelle-Calédonie.

42. Il y a plus de dix ans, en 1992 et en 2000, Paul Néaoutyine, à l'époque président du FLNKs s'était néanmoins rendu à la Quatrième Commission et au Comité de décolonisation pour y faire un discours. 
chain séminaire en Nouvelle-Calédonie ${ }^{43}$. En 2010, ce séminaire s'est effectivement déroulé à Nouméa du 18 au 20 mai.

Néanmoins, pour certains militants indépendantistes (entretien avec François Eïra Karé, militant indépendantiste kanak, février et mars 2012), les droits des peuples autochtones ont très peu de résonance politique aujourd'hui en Nouvelle-Calédonie. Actuellement, leurs usages et les revendications qui s'y rapportent se trouvent principalement dans le milieu associatif, notamment à travers le CNDPA, le Congrès populaire coutumier, le CAUGERN ${ }^{44}$, l'UNPK ${ }^{45}$, le sénat coutumier. En outre, le sénat coutumier s'est beaucoup impliqué dans la question des droits des peuples autochtones en raison de la venue du rapporteur spécial sur les droits des peuples autochtones, James Anaya, en mission en Nouvelle-Calédonie du 6 au 13 février 2011 pour évaluer la situation du peuple kanak. En septembre 2011, ce fut la première fois qu'un des présidents du sénat coutumier se rendait aux Nations unies à Genève pour assister à une réunion relative aux droits des peuples autochtones, et dans ce cas précis pour assister à la présentation du rapport de James Anaya au conseil des droits de l'Homme ${ }^{46}$.

\section{Stratégie de décolonisation et d'autochtonie de l'État}

Le changement de stratégie de certains leaders kanak pour les droits des peuples autochtones peut être bienvenu pour une France qui veut garder la Nouvelle-Calédonie française et qui a finalement accepté la Déclaration sur les droits des peuples autochtones en 2007. Dans l'intervention prononcée par le représentant de la France au sujet de l'adoption par l'Assemblée générale des Nations unies de la Déclaration sur les droits des peuples autochtones, mentionnée plus haut, celui-ci a expliqué que pour la France l'article 3 sur le droit à l'autodétermination doit s'exercer conformément aux normes juridiques que prévoit l'article 46, sous-entendu dans le cadre d'une autonomie interne.

Effectivement, la Déclaration sur les droits des peuples autochtones ne permet pas de porter atteinte à l'intégrité de l'État, donc de s'en séparer, donc de devenir un État indépendant, contrairement aux résolutions 1514 et 1541 dans lesquelles l'indépendance est une possibilité. Ainsi, ce changement de stratégie de certains leaders kanak qui se prononcent désormais pour la Déclaration sur les droits des peuples autochtones n'est en rien une menace pour la France puisque la Nouvelle-Calédonie dispose déjà d'une forte autonomie interne au sein de laquelle l'État a mis en place un programme d'autochtonie (Conseils coutumiers, Sénat coutumier, etc.).

L'État français a d'ailleurs eu depuis le début de la colonisation sa manière de régler la question autochtone, par la violence dès les premières décennies puis plus en douceur et de manière beaucoup plus feutrée après les violents conflits de l'insurrection jusqu'à ces dernières années. Au départ, comme l'explique Isabelle Leblic dans son ouvrage Les Kanak face au développement :

« c'est le service des Affaires indigènes, davantage fait pour contrôler et tenir en respect les Kanak que pour œuvrer en leur faveur, qui est chargé de l'application de cette réglementation. Ce sont d'ailleurs les gendarmes qui représentent les Affaires indigènes au sein des tribus. » (Leblic, $1993: 27$ )

Et ce jusqu'en 2009, date à laquelle ont été mis en place les « officiers coutumiers ». C'était une des manières dont l'État colonial gérait la question de l'autochtonie du pays. Aujourd'hui, les manières de faire se sont peut-être adoucies mais la question de la souveraineté autochtone est toujours subordonnée à celle de l'État.

Par ailleurs, l'État a toujours mis en place deux régimes d'état civil dans ses colonies, qui perdurent jusqu'à aujourd'hui en NouvelleCalédonie, à Mayotte et à Wallis-et-Futuna. Au départ, les Kanak étaient régis par le code de l'indigénat qui s'est appliqué en NouvelleCalédonie comme dans les autres colonies françaises à partir de 1887, et les plaçait hors de l'état civil de droit commun. Si le régime de l'indigénat a été aboli en 1946, deux statuts civils ont néanmoins perduré au sein de la République. Aujourd'hui en Nouvelle-Calédonie, il y a le statut civil de droit commun et le statut civil dit « coutumier $»^{47}$. L'expression «indigénat»

43. En effet, le Comité de décolonisation organise tous les ans un séminaire régional sur les questions de décolonisation. Une année le séminaire a lieu dans les Caraïbes, et l'année suivante il a lieu dans le Pacifique, et ainsi de suite.

44. Le CAUGERn est le Comité autochtone de gestion des ressources naturelles, créé en 2005 (Demmer, 2007) dont les activités sont beaucoup moins soutenues depuis un ou deux ans.

45. L'Union nationale pour le peuple kanak est issue du comité de coordination CNDPA qui faisait suite à une des branches issues de la division des membres du CNDPA. L'UNPK a été mis en place en 2009.

46. Ayant été dans les coulisses de l'organisation, la visite du rapporteur spécial sur les droits des peuples autochtones fera ultérieurement l'objet d'un autre article.

47. Le statut particulier fait l'objet de l'article 75 de la constitution française. 
prend sa racine dans le mot « indigène » qui a été remplacé ensuite par «autochtone » au niveau international d'abord, et par «coutumier » au niveau local de la Nouvelle-Calédonie.

Nous avons déjà parlé dans cet article de la création, initiée à Nainville-les-Roches, d'institutions « coutumières », donc « autochtones », c'est-à-dire le conseil consultatif coutumier d'abord, puis le sénat coutumier ensuite. En Guyane, la même stratégie de « gestion des affaires autochtones » a été mise en place au niveau institutionnel par l'État puisqu'il existe de même un conseil consultatif pour les peuples autochtones qui est le « conseil consultatif des populations amérindiennes et bushinenge de Guyane ». Son rôle est consultatif, comme pour le sénat coutumier, et il a aussi la possibilité de :

« s'exprimer sur tout projet ou proposition de délibération du conseil général ou du conseil régional de la Guyane emportant des conséquences sur l'environnement, le cadre de vie ou intéressant les activités culturelles des populations amérindiennes et bushinenge. » (http://www.guyane.pref.gouv.fr/conseil-consultatifdes-populations-amerindiennes-et-bushinenge-deguyane/, consulté le 15/03/2012)

\section{À l'approche de 2014...}

\section{Du côté de la France}

Depuis 1998, l'État tente d'effectuer en Nouvelle-Calédonie une « décolonisation originale », selon l'expression de Philippe Gomès ${ }^{48}$ (dans le discours qu'il a prononcé à New York, le 6 octobre 2009, lors de la $64^{\mathrm{e}}$ session de la Quatrième commission de l'Assemblée générale des Nations unies), qui se fasse dans la France ou en association avec la France. Voici ce que dit le président d'alors du gouvernement de Nouvelle-Calédonie :

« Ce nouvel accord, l'accord de Nouméa, est avant tout un accord de décolonisation original puisqu'il se déploie au sein de la France. »

L'État laissera probablement comme souplesse à ceux considérés comme citoyens de Nouvelle-Calédonie, de choisir entre un statut d'autonomie, tel que celui qui prévaut actuellement, et une indépendance-association. Nicolas Sarkozy, président de la République française, l'a dit, lors de ses vœux à l'Outre-mer depuis l'île de La Réunion en 2010 :
« Il n'y a qu'une seule ligne rouge : celle de l'indépendance. L'outre-mer est français et restera français " http://infoantilles.sasi.fr/web/infoantilles/Actualites. nsf/Actualites \%20Antilles\%20accueil/7748FFA9609 ED0AE042576B000530ECB?opendocument, consulté le 30/04/2012)

Puis toujours lors de ses vœux à l'Outre-mer en janvier 2011 :

« Je connais votre crainte. L'État jouera son rôle de contrôle, d'arbitre, de garant de l'unité de notre nation. Il n'est pas question de largage de l'Outremer. » (http://www.guadeloupe.franceantilles.fr/ regions/departementales/morceaux-choisis-des-vœuxde-nicolas-sarkozy-a-1-outre-mer-09-01-2011-108235. php, consulté le 30/04/2012)

Et il l'a redit lors de son discours des vœux aux Outre-mers à Cayenne, en Guyane, le 22 janvier 2012 :

«La France ne craint pas de vous donner plus de responsabilité sur les plans institutionnels, diplomatiques, économiques, culturels. [...] Je n'ai jamais été ambigu sur l'attachement de la France aux Outremers. J'appartiens à une famille politique qui n'a jamais considéré qu'il fallait accompagner les Outremers vers l'indépendance. »

Le président de la République a confirmé qu'aujourd'hui l'État accepte de laisser une certaine souplesse d'autonomie aux territoires et pays d'Outre-mer, mais refuse l'éventualité de l'indépendance. Si les partis politiques de droite se prononcent clairement sur cette question, le Parti socialiste est plus timide à s'exprimer à ce propos. En fait, il en est proche. Si François Hollande, candidat pour le PS aux élections présidentielles de 2012, a clairement dit « Je ne suis pas pour l'indépendance de la Polynésie française » (Tahiti Infos, 25/02/2012), il n'exprime pas sa position concernant la NouvelleCalédonie mais dit simplement qu'il veillera à ce que le choix des Calédoniens soit respecté (François Hollande 2012, « Mes 30 engagements pour les Outre-mers », programme pour l'élection présidentielle du 22 avril 2012). Mais voici ce qu'il dit dans son « discours aux Outre-mers » le 10 mars 2012 :

« La France, notre France, pour citer le poète Aimé Césaire, "est porteuse à tous les souffles du monde". Elle s'inspire de toutes les couleurs du monde, mais aussi de toutes ses cultures. La France est fière de sa multiplicité. La France est heureuse de ses métissages. Et la France grâce à vous est présente partout dans le monde. Nous sommes sans doute un des rares pays de la planète à pouvoir être partout, sur tous les continents du

48. Philippe Gomès, leader du parti politique Calédonie ensemble, était à l'époque président du gouvernement de NouvelleCalédonie. 
monde, pour influencer, pour porter, pour donner ce que nous avons de plus beau, c'est-à-dire notre langue, notre culture, nos produits, nos fabrications, bref tout ce que nous faisons ensemble au nom de la France. La France que j'aime, que vous aimez, c'est la France qui est capable de faire vivre ensemble ses différences. Il n'y a pas plusieurs France qui se feraient conflit. [...] Non, il y a la République, la République française une, indivisible et laïque. Et la République ne craint pas la diversité [...]. » (Souligné par nous)

\section{Au niveau local}

Deux ans avant l'échéance attendue et redoutée de 2014, le comité de pilotage sur l'avenir institutionnel de la Nouvelle-Calédonie s'est tenu les 14 et 15 février 2012 au hautcommissariat de la Nouvelle-Calédonie, en présence des signataires de l'accord de Nouméa, des représentants des collectivités calédoniennes, des parlementaires et des représentants des partis politiques représentés au congrès de la NouvelleCalédonie. Il avait pour objectif de contribuer à la préparation du choix que les responsables politiques auront à définir et les électeurs à trancher lors de la phase de consultation des Calédoniens qui sera organisée au cours du quatrième mandat du Congrès, soit entre 2014 et 2018 (cf. Site du haut-commissariat de la NouvelleCalédonie : (http://www.nouvelle-caledonie. gouv.fr/site/Actualites/15-fevrier-2012-Comitede-pilotage-Apres-2014§, consulté le 30/04/ 2012). Le travail effectué lors de ce comité a porté sur trois thèmes sur lequel lesdits citoyens de Nouvelle-Calédonie auront à s'exprimer au moment de la consultation, c'est-à-dire l'accès à un statut international de pleine souveraineté, le transfert des compétences régaliennes et la transformation de la citoyenneté en nationalité. Ces deux jours ont été consacrés à la question de l'accès à un statut international de pleine souveraineté. Un conseiller législatif des États fédérés de Micronésie ${ }^{49}$ est venu présenter la situation institutionnelle de son pays ( $c f$. Site $\mathrm{du}$ haut-commissariat de la Nouvelle-Calédonie : http://www.nouvelle-caledonie.gouv.fr/site/ Actualites/15-fevrier-2012-Comite-de-pilotageApres-2014).

On constate que dans les thèmes discutés lors du comité sur l'après-2014, la compé- tence régalienne de la sécurité extérieure (diplomatie et défense) a été divisée en deux thèmes différents puisque la question du statut international, et donc de la diplomatie, sera posée à part de la question du transfert des compétences régaliennes ( $c f$. Site du haut-commissariat de la Nouvelle-Calédonie : http://www.nouvellecaledonie.gouv.fr/site/Actualites/15-fevrier-2012Comite-de-pilotage-Apres-2014). Ceci permettra, en effet, une réduction du risque de la perte par la France du territoire de NouvelleCalédonie à l'issue de la consultation, puisqu'à l'inverse d'une seule question qui serait pour ou contre le transfert de la totalité des compétences régaliennes, trois questions sur différents aspects des compétences régaliennes seront éventuellement posées et pourront diviser les indépendantistes entre eux. Car on peut faire l'hypothèse que si l'indépendance-association avec la France était une option rejetée par les indépendantistes durant les années $1980^{50}$, elle ne l'est peut-être plus autant aujourd'hui.

On comprend par ailleurs à travers les discours des acteurs locaux non indépendantistes, notamment le discours de Philippe Gomès en 2009 devant la Quatrième commission :

«C'est sur le socle de cette reconnaissance mutuelle que la décolonisation a été entreprise, une décolonisation pour rassembler, non pour exclure, une décolonisation destinée à "refonder un lien social durable entre les communautés qui vivent aujourd'hui en NouvelleCalédonie, en permettant au peuple kanak d'établir avec la France des relations nouvelles correspondant aux réalités de notre temps [...]" " (Discours de Philippe Gomès, président du gouvernement de la Nouvelle-Calédonie, Assemblée générale de l'onU, New-York, 6/10/2009)

et celui de Pierre Frogier au congrès de la Nouvelle-Calédonie :

«Une Nouvelle-Calédonie que nous, au Rassemblement, nous voulons, au sein de la République française. » (Intervention de Pierre Frogier au congrès de la Nouvelle-Calédonie, 25/03/2011)

quelle est la forme d'autodétermination qu'ils prévoient pour l'avenir. Les positions des leaders non indépendantistes varient entre autonomisme et « autonomisme-ultra ». De même, les discours des leaders indépendantistes varient

49. Les États fédérés de Micronésie, précédemment sous tutelle japonaise, sont sous tutelle américaine depuis 1944 et ont obtenu le statut international de pleine souveraineté depuis 1986. C'est un territoire indépendant en libre association avec les États-Unis. Ils ont un siège aux Nations unies depuis 1991. La libre association avec les États-Unis est régie par le « Compact of free association ", signé le $1^{\mathrm{er}}$ août 1982. Les États-Unis gèrent notamment la défense, la politique étrangère et la sécurité des États fédérés de Micronésie. Ainsi, les compétences régaliennes sont partagées entre les États-Unis et les États fédérés de Micronésie.

50. En janvier 1985, le plan Pisani prévoyait pour le mois de septembre un référendum qui devait offrir le choix entre l'accession du territoire à l'indépendance dans le cadre d'une association étroite avec la France et la poursuite de l'administration française, au titre d'un statut d'autonomie révisé (A/AC.109/892). 


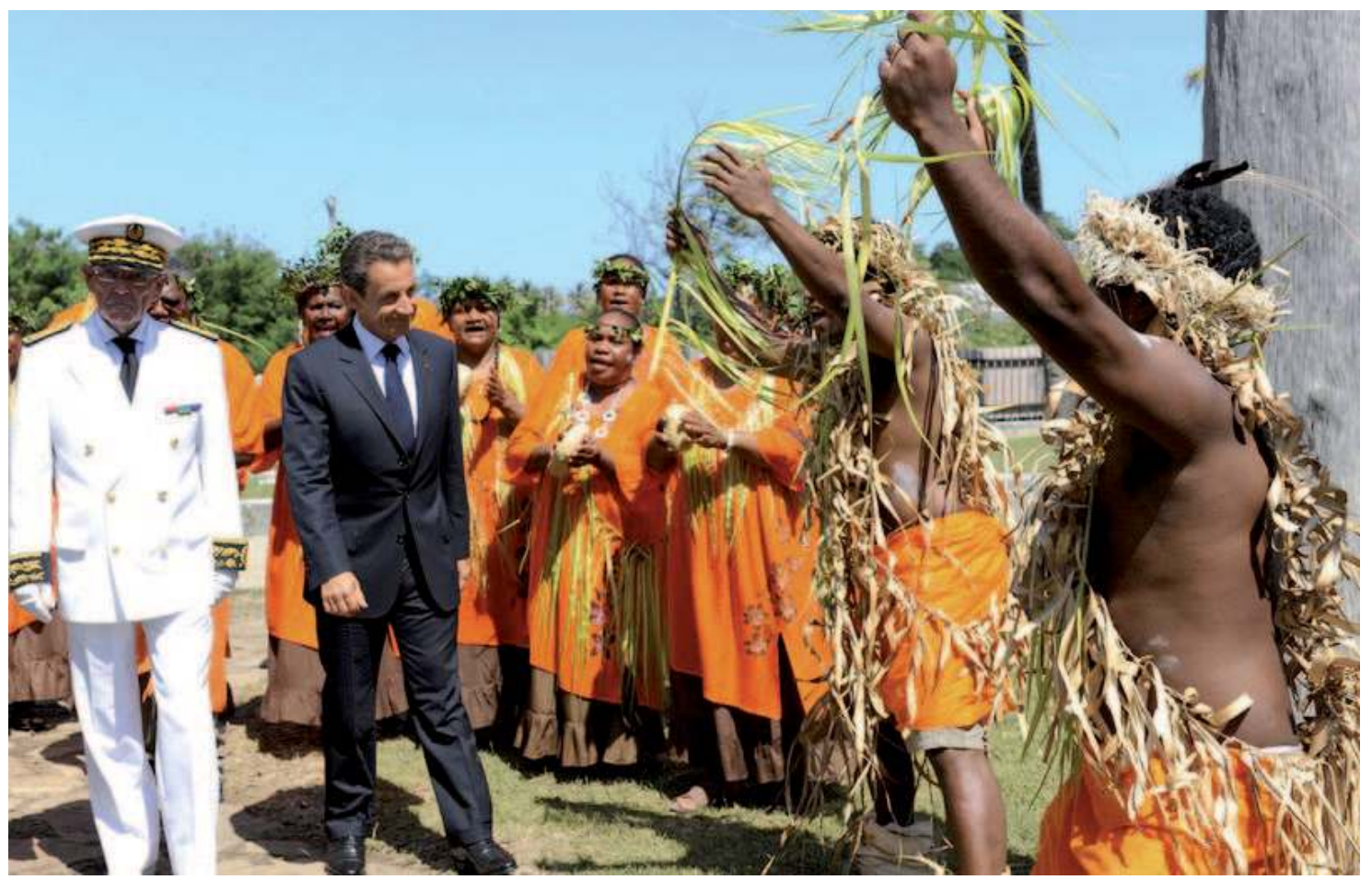

Рното 7. - Nicolas Sarkozy en visite au Sénat coutumier, Nouméa, Nouvelle-Calédonie, août 2011 http://www.lefigaro. fr/politique/2011/08/28/01002-20110828ARTFIG00264-sarkozy-plaide-la-decrispation-en-nouvelle-caledonie.php, consulté le $01 / 05 / 2012$ )

entre « indépendantisme modéré », « indépendantisme en faveur d'une indépendanceassociation » et « indépendantisme total». La frontière entre ceux que l'on appelait les « loyalistes » et ceux que l'on appelle les indépendantistes est bien plus floue que pendant les années 1980 et des leaders de tendance de droite, donc traditionnellement contre l'indépendance, peuvent se retrouver sur nombre de points avec desdits indépendantistes dans la catégorie des « autonomistes ultra ».

\section{Au niveau régional et international}

Par ailleurs, au sein des institutions régionales et internationales, le FLNKS est petit à petit remplacé par les représentants des institutions de Nouvelle-Calédonie. Cette forme de représentation internationale était d'ailleurs une des propositions qui avaient déjà été faites par l'État au moment de Nainville-les-Roches ${ }^{51}$ et que Nicolas Sarkozy a réaffirmé dans son discours pour les vœux aux Outres-mers à Cayenne, en disant que :

« les élus des outre-mers, je souhaite que vous puissiez représenter la France dans les organisations régionales. [...] La République française n'a qu'avantage à faire confiance aux élus que vous avez choisis pour parler dans les organisations régionales pour que ce ne soit pas des diplomates ou technocrates parisiens qui ne connaissent pas le territoire qui parlent à votre place. [...] Les départements et les territoires d'outre-mer vous serez désormais les avant-postes de la République française. »

À travers la Nouvelle-Calédonie, territoire français, c'est finalement la France qui est présente dans ces institutions régionales et internationales. En 2009, ce fut la première fois qu'une délégation commune, composée de membres indépendantistes et non indépendantistes, du gouvernement de Nouvelle-Calédonie se rendait à une session de la Quatrième commission de l'Assemblée générale des Nations unies sur la

51. «Monsieur le ministre estime que la Nouvelle-Calédonie doit être associée à tout ce qui touche son environnement et met en jeu ses intérêts sociaux, économiques et culturels dans le Pacifique. L'exercice de ses compétences doit pouvoir comporter l'association du territoire sous quatre formes : [...] - représentation du territoire dans les organisations économiques, sociales et culturelles du Pacifique Sud y compris la CPS. " (5 jours à Nainville-les-Roches, secrétariat d'Etat aux DOM-TOM). 
décolonisation $^{52}$. Et aujourd'hui, c'est seulement au sein du Groupe mélanésien Fer de Lance que le FLNKs seul est représenté. Des demandes ont déjà été faites de la part du gouvernement de Nouvelle-Calédonie pour que ce soit une délégation du gouvernement de Nouvelle-Calédonie qui se rende à l'avenir au Groupe mélanésien Fer de Lance.

\section{Perspectives}

De leur côté, les représentants du sénat coutumier, prenant exemple sur le parlement Sami de Norvège notamment ${ }^{53}$, demandent à avoir un rôle décisionnel et non plus consultatif. On bascule donc de revendications de souveraineté d'indépendance étatique à des revendications de souveraineté autochtone d'autonomie interne renforcée. Ainsi dans ce cadre, l'autodétermination serait celle d'une autonomie interne comme le prévoit la Déclaration sur les droits des peuples autochtones.

À « indépendance » et "décolonisation 》 revendiquées par les indépendantistes kanak, la France a opposé "autodétermination» et «autochtonie». Une autodétermination qu'elle a interprétée et tente de mettre en usage dans le sens de celle de l'autochtonie, donc des droits de l'homme, des droits individuels et de l'autodétermination interne.

Aborder la question en termes de souveraineté permet d'orienter différemment le regard. La France "lâche» de la souveraineté à la Nouvelle-Calédonie en termes d'autonomie, donc de compétences locales. En effet, dans ce cadre, donner plus d'autonomie donc de compétences locales n'ébranle en rien sa souveraineté sur le territoire et en plus cela coûte moins cher pour elle. La France tente en Nouvelle-Calédonie une « décolonisation originale » afin d'éviter pour elle la perte de souveraineté sur un territoire qui lui apporte beaucoup en termes économique, géopolitique, maritime, militaire, etc.

Pousser les limites de l'autonomie interne, autochtone ou non, au plus proche de l'indépendance, satisfaire les désirs de souveraineté et de pouvoir de chacun des protagonistes, indépendantistes ou non, permettra peut-être à la France de faire oublier la question de l'indépendance et de garder ses intérêts en Nouvelle-Calédonie.

\section{BIBLIOGRAPHIE}

Accords de Matignon-Oudinot, 26 juin \& 20 août 1988. Accord de Nouméa, 5 mai 1998.

Alfredsson Gudmundur, 1993. The right of selfdetermination and indigenous peoples, in C. Tomuschat (ed.), Modern Law of Self-Determination, Dordrecht, M. Nijhoff Publ., pp. 41-54.

Anaya James, 2004 ( $2^{\text {nd }}$ ed.). Indigenous Peoples in International Law, New York, Oxford University Press.

BaIsSAT Bernard, 2006. La grande tournée outre-mer du Général De Gaulle, documentaire, $52 \mathrm{mn}$.

Buso Laurie et Guillaume CHoux, 2012 (janviermars). Les rouages de l'affaire Greenpeace: du secret d'État à la publicité internationale, Perspectives internationales 1, pp. 34-69.

Chakma Suhas, 2002. The Use of UN Human Rights Mechanisms by Indigenous Peoples: Past Practices and Emerging Challenges, Indigenous Affairs 1, pp. 26-31.

Chatenet Pierre, 1988. Décolonisation. Souvenirs et réflexions, Paris, Éd. Buchet/Chastel.

Christnacht Alain, 2004. La Nouvelle-Calédonie, Paris, La Documentation française.

Constant Fred, 1987. La politique française de l'immigration antillaise de 1946 à 1987, Revue européenne de migrations internationales 3,3 , Les Antillais en Europe, pp. 9-30 (http://www.persee. fr/web/revues/home/prescript/article/remi_07650752_1987_num_3_3_1142, consulté le 29/04/ 2012).

Corntassel Jeff, 2008. Toward Sustainable SelfDetermination: Rethinking the Contemporary Indigenous-Rights Discourse, Alternatives 33, pp. 105-132.

CRISTESCU Aureliu, 1981. Le droit à l'autodétermination. Développement historique et actuel sur la base des instruments des Nations unies, par le rapporteur spécial de la sous-commission de la lutte contre les mesures discriminatoires et de la protection des minorités, New York, Nations unies.

Culmann Henri, 1950. Union française, Paris, PuF, coll. "Que sais-je ».

Demmer Christine, 2007. Autochtonie, nickel et environnement. Une nouvelle stratégie kanak, Vacarme 39 , pp. 43-48.

FOSTER Robert J., 1995. Nation making. Emergent Identities in Postcolonial Melanesia, Ann Arbor, The University of Michigan Press.

Gabriel Claude et Vincent Kermel, 1985. NouvelleCalédonie. La révolte kanake, Paris, La Brèche.

52. Cette délégation était composée de Bernard Deladrière, chargé du budget, de la fiscalité et de l'économie numérique et Yann Devillers, chargé des infrastructures publiques et des transports, de Léonard Sam, premier vice-président du congrès de la Nouvelle-Calédonie, Jean-Pierre Djaiwe, premier vice-président de la province Nord, de Sonia Lagarde, troisième viceprésidente de la province Sud, et de Damien Yeiwéné, conseiller de la province des Îles Loyauté.

53. Le parlement Saame de Norvège est une assemblée législative. 
GrafF Stéphanie, 2009 (janvier). NouvelleCalédonie : un pays à décoloniser, Les Nouvelles Survival 70, p. 15.

KIRSCH Stuart, 2006. Reverse Anthropology. Indigenous Analysis of Social and Environmental Relations in New Guinea, Palo Alto, CA, Stanford University Press.

LEBLIC Isabelle, 1993. Les Kanak face au développement. La voie étroite, Grenoble, Presses universitaires de Grenoble.

_, 2003a. Présentation : Nouvelle-Calédonie, 150 ans après la prise de possession, in I. Leblic (éd.), Journal de la Société des Océanistes 117 : NouvelleCalédonie, 150 ans après la prise de possession, pp. 135-145.

-, 2003b. Chronologie de la Nouvelle-Calédonie (1853-2003), in I. Leblic (éd.), Journal de la Société des Océanistes 117 : Nouvelle-Calédonie, 150 ans après la prise de possession, pp. 299-312.

—, 2007. Kanak identity, new citizenship building and reconciliation in New Caledonia, Journal de la Société des Océanistes 125, pp. 271-282.

MonNerie Denis, 2005. La Parole de notre Maison, Discours et cérémonies kanak aujourd'hui (NouvelleCalédonie), Paris, CNRs Éditions et Éditions de la maison des sciences de l'homme.

NAtions UnIES, 1945. Charte des Nations unies, chapitre XI, Déclaration relative aux territoires non autonomes, article 73 et 74 .

—, 1960. Déclaration sur l'octroi de l'indépendance aux pays et aux peuples coloniaux, résolutions 1514 et 1541.

_, 1987. Étude du problème de la discrimination à l'encontre des populations autochtones, par José R. Martinez Cobo, rapporteur spécial de la souscommission de la lutte contre les mesures discriminatoires et de la protection des minorités, vol. V, New York, E/CN.4/Sub.2/1986/7/Add.4.

—, 1996 (10 juin). Conseil économique et social, Commission des droits de l'homme, sous-commission de la lutte contre les mesures discriminatoires et de la protection des minorités, Groupe de travail sur les populations autochtones, quatorzième session, 29 juillet-2 août 1996, activités normatives : évolution des normes concernant les droits des autochtones, document de travail du président-rapporteur, $\mathrm{M}^{\mathrm{me}}$ Erica-Irene A. Daes sur la notion de «peuple autochtone », E/CN.4/Sub.2/AC.4/1996/2.

—, 2007. Déclaration des Nations unies sur les droits et les libertés fondamentales des populations autochtones, A/HRC/1/L.3.

_, 2011. Rapport du Rapporteur Spécial sur les droits des peuples autochtones, Monsieur James Anaya. La situation du peuple kanak en Nouvelle-Calédonie. A/HRC/18/35/Add.6.

PAGE Jeanne, 2000. Du partage des compétences au partage de la souveraineté : des TOM aux POM, thèse de droit, Université d'Aix-Marseille.

SAussol Alain, 1979. L'héritage. Essai sur le problème foncier mélanésien en Nouvelle-Calédonie, Paris, Société des Océanistes, coll. Publications de la Société des Océanistes 19.

SCHULTe-TENCKHOFF Isabelle, 1997. La question des peuples autochtones, Paris/Bruxelles, LJDG/ Bruylant, coll. « Axes Savoir ».

-, 2012. Treaties, peoplehood and self-determination: understanding the language of Indigenous rights, in E. Pulitano (ed.), Indigenous Rights in the Age of the UN Declaration, Cambridge University Press, p. 64-86

Schulte-Tenckhoff Isabelle \& Adil Hasan Khan, 2011. The Permanent Quest for a Mandate. Assessing the UN Permanent Forum on Indigenous Issues, Griffith Law Review 20, 3, pp. 673-701.

Smouts Marie-Claude, 1979. La France à l'onu, Paris, Presses de la Fondation nationale des Sciences politiques.

ThORnBerry Patrick, 2002. Indigenous Peoples and Human Rights, Manchester, Manchester University Press.

WamYTaN Rock, 2003. La révision constitutionnelle du 17 mars 2003 au regard du droit international des peuples à disposer d'eux-mêmes. Conséquences pour la Nouvelle-Calédonie et les pays d'outre-mer, Paris, ms. 